HAMZA Gábor

DOI: 10.15170/DIKE.2019.03.02.10

Em. Prof. Dr. iur. DDr. h.c.

Ordentliches Mitglied der Ungarischen Akademie der Wissenschaften

Eötvös Loránd Universität (ELTE), Budapest

\title{
Grenzfragen von den Pariser Vorortverträgen bis zum Ersten Wiener Schiedsspruch 1938 und seine Folgen
}

\begin{abstract}
Border Questions from the Treaties Signed in the Suburbs of Paris to the First Vienna Award 1938 and its Consequences

The first part of the article is dealing with the political negotiations, in particular, the one after the Munich Agreement, defining a three-month period to resolve Hungarian demands, to the First Vienna Award signed on November 2, 1938 at the Belvedere Palace in Vienna. The First Vienna Award separated predominantly Hungarian-populated territories in southern Slovakia and southern Carpathian Rus from Czechoslovakia and awarded them to the Kingdom of Hungary. Hungary thus regained some of the territories in present-day Slovakia and Ukraine lost in the Peace Treaty of Trianon. In the second part of the study the author is analyzing the negotiations following the First Vienna Award. The recovered territories were incorporated into Hungary (Kingdom of Hungary) on November 12, 1938, by a legislative act of the Hungarian Parliament.
\end{abstract}

Keywords: Antikominternpakt, "appeasement", Austritt Ungarns aus dem Völkerbund, Autonomie der Karpatho-Ukraine, Autonomie der Slowakei, Bardo-Vertrag (Traité de Bardo), "der kleine Krieg” ("mala vojna"), Friedensvertrag von Lausanne, Friedensvertrag von Neuilly-sur-Seine, Friedensvertrag (Staatsvertrag) von Saint-Germain-en-Laye, Friedensvertrag von Sèvres, Friedensvertrag von Trianon, "Kleine Entente", lettre d'envoi d'Alexandre Millerand, Münchener Abkommen, Reichsprotektorat Böhmen und Mähren, "Schutzvertrag", Verbandlungen in Komárom (Komarno)

\section{Die Vorgeschichte}

Der Friedensvertrag (Traité de paix) von Trianon, einer der sog. Pariser Vorortverträge wurde am 4. Juni 1920 unterzeichnet. ${ }^{1}$ Durch diesen Friedensvertrag ging etwa 71,4 Prozent des Staatsgebiets und 63,6 Prozent des Staatsvolkes (der Staatsbevölkerung) des Königreichs Ungarn einschließlich des Nebenlands (ungarisch: társország) - mit weitgehender Autonomie - KroatienSlawonien verloren. Von $325.411 \mathrm{~km}^{2}$ - das Territorium von Kroatien-Slawonien belief sich auf $42.527 \mathrm{~km}^{2}$ - blieben $93.073 \mathrm{~km}^{2}$. Der Friedensvertrag mit Deutschland (dem Deutschen Reich),

\footnotetext{
1 Hinsichtlich des französischsprachigen Textes des Friedensvertrages von Trianon siehe: Allied and Associated Powers (1914-1920). Traité de paix entre les Puisssances alliées et associées et la Hongrie, protocole et déclaration du 4 juin 1920 (Trianon), Paris 1920.
} 
der auch hohe Reparationszahlungen an die Siegermächte vorsah, wurde am 28. Juni 1919 im Spiegelsaal (Salle des Glaces) von Versailles unterzeichnet. ${ }^{2}$ Der Friedensvertrag bzw. Staatsvertrag $^{3}$ von Saint Germain-en-Laye mit Deutsch-Österreich wurde am 10. September 1919 unterzeichnet. ${ }^{4}$ Der Zusammenschluss von Deutsch-Österreich mit dem Deutschen Reich wurde untersagt. Der Friedensvertrag von Neuilly-sur-Seine mit Bulgarien wurde am 27. November 1919 unterschrieben. ${ }^{5}$ Dieser Friedensvertrag mit dem Osmanischen Reich bzw. mit der Türkei (dem Nachfolgestaat des Osmanischen Reiches) wurde am 10. August 1919 unterzeichnet. Der Friedensvertrag von Sèvres, der vom türkischen Parlament nicht ratifiziert wurde, wurde durch den Friedensvertrag von Lausanne am 24. Juli 1923 weitgehend revidiert - zugunsten der Türkei bzw. außer Kraft gesetzt. Der Friedensvertrag von Lausanne wurde nach schwierigen Verhandlungen, die acht Monate lang dauerten, unterzeichnet.

Der Friedensvertrag von Trianon schrieb auch eine schwerwiegende Wiedergutmachung vor, deren Summe und Details aber später festzulegen waren. ${ }^{6}$ Hier ist darauf zu verweisen, dass der Friedensvertrag mit Deutsch-Österreich keine Reparationsforderungen vorsah. Wichtig ist für das Folgende, dass Art. 19 des Völkerbundstatuts die Möglichkeit einer friedlichen Revision der völkerrechtlichen Verträge, einschließlich der Staatsgrenzen, vorsah. Mit Rücksicht auf diesen Artikel traf am 20. Februar 1920 die ungarische Regierung die Entscheidung, dass sie nach dem Abschluss des Friedensvertrages um die Aufnahme in den Völkerbund bitten wird, um die Revision der schwierigen Bedingungen des Friedensvertrages zu erreichen ${ }^{7}$.

Der Friedensvertrag von Trianon wurde von der ungarischen Nationalversammlung (ungarisch: Nemzetgyúlés) am 26. Juni 1921 durch den Gesetzesartikel 1921: XXXIII ratifiziert. Maßgeblich dafür war ein ,lettre d'envoi" von Alexandre Millerand, der die Änderung der Grenzen ermöglichte. Der Abgeordnete Margain betonte, dass die Existenz dieser „Note“ „Beweis“ für die Absurdität der neuen Grenzen ist. Selbst Ministerpräsident und Außenminister Aristide Briand war der Meinung, dass die neuen Staatsgrenzen ,ziemlich willkürlich“ (sic!) gezogen worden sind. Nach Briand verstoßen die neuen Grenzen gegen gewisse Interessen und bedürfen einer Korrektur. Im Unterhaus (House of Commons) von Großbritannien hat am 25. März 1920 der Abgeordnete

\footnotetext{
2 Die Summe der Reparationszahlungen des Deutschen Reiches wurden erst im Jahre 1921 festgelegt. Die Summe belief sich auf 132 Milliarden Goldmark d.h. auf 31,5 Milliarden US-Dollar.

${ }^{3}$ Hier ist darauf zu verweisen, dass der mit Deutsch-Österreich unterzeichnete Friedensvertrag von Saint Germainen-Laye eigentlich ein Staatsvertrag war. Dies lässt sich darauf zurückführen, dass der Signatarstaat Deutsch-Österreich während des Ersten Weltkrieges noch nicht existierte: BRAUNEDER, Die Republik entsteht 162 ff., $121 \mathrm{ff}$.

${ }^{4}$ Der Friedensvertrag bzw. Staatsvertrag von Saint-Germain-en-Laye hat zwar die Verpflichtung von DeutschÖsterreich zur Zahlung von Reparationskosten festgelegt, hat aber deren Summe nicht bestimmt. Die Summe der Reparationskosten wurde auch später nicht festgelegt.

${ }^{5}$ Die Summe der Reparationszahlungen Bulgarien wurde auf 2,25 Milliarden Goldfranc festgelegt. Bulgarien hat bis zum Jahre 192830 Millionen Goldfranc, zu etwa 90 Prozent in Form von Warenlieferungen, gezahlt.

${ }^{6}$ Die Friedensbedingungen werden Ungarn am 15. Januar 1920 überreicht. Den Friedensvertrag von Trianon haben die Beauftragten der kurzlebigen Regierung von Sándor Simonyi-Semadam (Ministerpräsident vom 15. März bis 19. Juli 1920), Agoston Benárd und Alfréd Drasche-Lázár im Grand Palais du Trianon unterschrieben. Den Friedensvertrag haben die Vertreter der Großmächte (Frankreich, Großbritannien, Japan und Italien) und die Vertreter von 18 Staaten, d.h. insgesamt 22 Staaten - den Posten des Präsidenten (Vorsitzenden) der Unterzeichnungszeremonie nahm Alexandre Millerand wahr - unterzeichnet.

${ }^{7}$ Die im April 1921 gebildete Betblen-Regierung bat offiziell am 23. Mai 1921 in Genf um die Aufnahme Ungarns in den Völkerbund. Dem Antrag Ungarns wurde aber wegen der Burgenland-Frage nicht stattgegeben. Ungarn, als erster Verliererstaat, wurde am 18. September 1922 durch die Generalversammlung (Assemblée Générale) des Völkerbundes in Genf einstimmig in den Völkerbund aufgenommen. Deutschland trat erst am 8. September 1926 dem Völkerbund bei.
} 
(deputy) Captain Elliot gegen die Ratifikation des Friedensvertrags von Trianon protestiert. Einige Tage später, am 30. März 1920, haben im House of Lords Lord Newton, Viscount James Bryce, Lord Montagu, Lord Sydenham, Lord Weardale und Margues of Creewe das Wort im Interesse von Ungarn ergriffen. Die Debatten wegen der Ratifikation dauerten noch bis Mai 1921. 60 Abgeordnete (deputies) forderten die Ablehnung der Ratifikation des Friedensvertrages von Trianon. ${ }^{8}$

Ungarn schloss einen Sonderfrieden (Separatfrieden) mit den Vereinigten Staaten von Amerika (USA), der am 29. August 1921 in Budapest durch den Beauftragten der USA in Ungarn, Ulysses Grant-Smith und dem ungarischen Außenminister, Graf Miklós Bánffy (1873-1950) Außenminister vom 14. April 1921 bis 19. Dezember 1922 in der Regierung von Graf István Bethlen - unterschrieben wurde. ${ }^{9}$ Der Senat der USA hatte nämlich die mit Deutschland ${ }^{10}$, DeutschÖsterreich und Ungarn abgeschlossenen Pariser Vorortverträge nicht ratifiziert. ${ }^{11}$ Die Friedensverhandlungen führte auf ungarischer Seite Graf Miklós Bánffy. Im Hinblick auf die neuen Staatsgrenzen ist der Text des Friedensvertrags von Trianon mit dem mit den USA abgeschlossenen Sonderfriedensvertrag identisch. Die ungarische Nationalversammlung ratifizierte den Friedensvertrag von Trianon und den mit den USA abgeschlossenen Friedensvertrag, dessen Text das Völkerbundstatut nicht enthielt, am 13. Dezember durch den Gesetzesartikel 1921: XXXIII. ${ }^{12}$

Marchese Pietro Tomasi Della Torretta (1873-1962), der das Amt des Außenministers Italiens zwischen 7. Juli 1921 und 26. Februar 1922 in der Regierung von Ivanoe Bonomi innehatte - er war früher (vom 20. August 1919) Botschafter Italiens in Wien - hat den „Kompromiss” zwischen Österreich und Ungarn im Hinblick auf das Burgenland (auch Deutsch-Westungarn genannt) vermittelt. Dazu fand am 26. September 1921 eine Besprechung zwischen Edvard Beneš und dem ungarischen Außenminister Graf Miklós Bánffy statt. Im Laufe dieser Verhandlungen versprach Beneš die Unterstützung der territorialen Ansprüche Ungarns im Hinblick auf Sopron und seine Umgebung (acht Dörfer) durch die Tschechoslowakei. Darüber wurde dann das Abkommen zwischen Österreich und Ungarn in Venedig (Abkommen von Venedig) im Oktober 1921 (die Verhandlungen dauerten vom 11. bis 13. Oktober) unterzeichnet. Ungarn war in Venedig durch den Ministerpräsidenten Graf István Betblen und den Außenminister Graf Miklós Bánffy vertreten. Als Folge des Abkommens von Venedig fand ein Referendum (Volksentscheid) am 14.

\footnotetext{
8 Im französischen Parlament wurde der Friedensvertrag von Trianon vom Abgeordneten (député) Guernier zur Ratifikation vorbereitet.

${ }^{9}$ Hinsichtlich des Textes des Friedensvertrages mit den Vereinigten Staaten von Amerika siehe: United States. Treaty between the United States and Hungary Establishing Friendly Relations, Signed at Budapest, August 29, 1921. Washington D.C., 1922.

${ }^{10}$ Der von der deutschen Nationalversammlung am 23. Juni 1919 mit 237 gegen 138 Stimmen gebilligte Versailler Friedensvertrag wurde am 28. Juni in Versailles unterzeichnet. Erwähnung verdient, dass Ministerpräsident Philipp Scheidemann schon vorher, am 20. Juni 1919, aus Protest gegen die Bedingungen des Versailler Friedensvertrages zurückgetreten war. Am 10. Januar 1920 trat der Versailler Friedensvertrag und die Völkerbundsatzung in Kraft. Am 19. März 1920 wurde der Versailler Vertrag im Senat der USA abgelehnt. Der Friedensvertrag zwischen den Vereinigten Staaten von Amerika (USA) und Deutschland wurde am 25. August 1920 unterzeichnet.

${ }^{11}$ Hier ist darauf zu verweisen, dass der Friedensvertrag von Trianon auch von Polen nicht ratifiziert wurde. Dies war vor allem darauf zurückzuführen, dass Ungarn im Jahre 1920 den neuen polnischen Staat im Krieg gegen Sowjetrußland mit Waffenlieferungen unterstützt hat. Der im Jahre 1921 in Riga abgeschlossene Friedensvertrag zwischen Polen und Sowjetrußland hat für Polen vorteilhafte Grenzen bestimmt. Das Staatsgebiet Polens belief sich auf $388.900 \mathrm{~km}^{2}$.

12 Die Vereinigten Staaten von Amerika hatten im Völkerbund nur Beobachterstatus (non member observer state).
} 
Dezember 1921 in Sopron (auf Deutsch: Ödenburg), am 15. Dezember in Brennbergbánya und am 16. Dezember in acht Dörfern (Ágfalva, Balf, Bánfalva, Boz, Fertőrákos, Harka, Kópháza und Nagycenk) in der Umgebung von Sopron unter der Kontrolle der Kommission der Generäle der Entente-Mächte - General Hamelin (Frankreich), General Carlo Ferrario (Italien) und General Gorton (Großbritannien) - statt. ${ }^{13}$

Das Ergebnis des Referendums: Ungarn wurden $355 \mathrm{~km}^{2}$ belassen, die Stadt Sopron (deutsch: Ödenburg) und sechs Dörfer, von $4350 \mathrm{~km}^{2}$ gemäss dem Friedensvertrag von Saint Germain-en-Lay, der die Abtretung von Burgenland - der westliche Streifen der Komitate (ungarisch: vármegye) Pozsony, Moson, Sopron und Vas - vorsah und der am 10. September 1919 mit Deutsch-Österreich unterzeichnet wurde. ${ }^{14}$ Die Grenzkorrektion wurde durch den ungarischen Gesetzesartikel 1922: XXIX festgelegt und Sopron von der ungarischen Nationalversammlung das Attribut „Civitas Fidelissima” verliehen. Nach dem Zerfall des Königreichs Ungarn waren übrigens fünf kurzlebige, provisorische Staatsgebilde entstanden, nämlich die Republik von Banat (auf Ungarisch: Bánáti Köztársaság), die Wendländische Republik (ungarisch: Vendvidéki Köztársaság), die Republik von Baranya (ungarisch Baranyai Köztársaság), der Leitha Banschag (ungarisch: Lajtabánság) und Freistaat Fiume (italienisch: Libera Città di Fiume, ungarisch: Fiumei Szabad állam). ${ }^{15}$

Aufgrund des „lettre d'envoi", überreicht mit dem endgültigen Text des Friedensvertrages im Namen des Obersten Rates der Entente am 6. Mai 1920 in Paris von dem Präsidenten der Friedenskonferenz Alexandre Millerand (1859-1943) ${ }^{16}$ - Ministerpräsident und Außenminister von Frankreich vom 18. Februar bis 24. September und Staatspräsident (chef de l'État) bis 1924 wurde eine Kommission zur Festlegung der neuen Staatsgrenzen zustande gebracht. Entsprechend dem Vorschlag dieser Kommission entschied am 17. September 1922 der Rat des Völkerbundes (Conseil de la Société des nations), dass einige Dörfer an Ungarn rückgegliedert werden sollen. Es waren dies aufgrund der Entscheidung des Rates des Völkerbundes am 23. April 1923 zwei Dörfer bei Salgótarján $\left(27 \mathrm{~km}^{2}\right)$. Entsprechend Art. 19 des Völkerbundstatuts war ja die friedliche Revision der in den Pariser Vorortverträgen festgelegten Grenzen - eher theoretisch - möglich. ${ }^{17}$

\footnotetext{
13 Das Ergebnis der Volksabstimmung wurde am 17. Dezember bekanntgegeben. 65,8 Prozent der Wähler stimmten für den Verbleib in Ungarn. Der Rat der Botschafter nahm am 20. Dezember 1921 abgehaltenen Sitzung das Resultat des Volksentscheids zur Kenntnis.

${ }^{14}$ Hier sei darauf verwiesen, dass ein Bundesverfassungsgesetz Österreichs vom Jahre 1921 Sopron (Ödenburg) als Hauptstadt von Burgenland bestimmte.

15 Der Freistaat Fiume, der von 1920 bis 1924 bestand, wurde im Jahre 1921 von Frankreich, Großbritannien und den Vereinigten Staaten von Amerika anerkannt. Die Wendländische Republik hingegen wurde nur von DeutschÖsterreich (Österreich) anerkannt.

${ }^{16}$ Der „Lettre d'envoi"von Alexandre Millerand wurde von der Friedenskonferenz erst am 18. Mai 1920 der ungarischen Friedensdelegation zugestellt. An diesem Tage hielt die ungarische Friedensdelegation ihre letzte (feierliche) Sitzung und es wurde auf Vorschlag von Graf Albert Apponyi ihre Auflösung der Friedensdelegation beschlossen.

17 Aufgrund eines zwischen Polen und der Tschechoslowakei im Jahre 1920 abgeschlossenen Abkommens waren $589 \mathrm{~km}^{2}$ (kleine Teile der Komitate von Árva und Szepes) Polen zugefallen. Vom Komitat Árva werden 14, vom Komitat Szepes 13 Dörfer an Polen abgetreten: DORIAN, La question d'une frontière commune entre la Pologne et la Hongrie, Warszawa 1921. Der Verfasser dieser Abhandlung war Adorján Divéky (1880-1965), der den Pseudonym A. Dorian benutzte.
} 


\section{Die ersten Versuche des „appeasement“(„Verständigungspolitik“)}

Die Errichtung der sog. kleinen Entente (Petite Entente, Little Entente) ${ }^{18}$ erfolgte durch den SHS-Staat (Königreich der Serben, Kroaten und Slowenen, ab 1929 Jugoslawien), Rumänien und die Tschechoslowakei durch mehrere Verträge ab 1920. Am 14. Juni 1938 besuchte Wilhelm Keitel (Generalstabchef der Wehrmacht vom 5. Februar 1938 bis 30. April 1945) Ungarn (Budapest). Im Laufe der Verhandlungen wird die Möglichkeit der Kooperation zwischen dem Generalstab von Deutschland und dem von Ungarn besprochen. Die Pläne werden aber nicht konkretisiert. Vorwürfe der Mitglieder der ungarischen Delegation bemängelten die deutschen Waffenlieferungen. Die politische und militärische Führung von Deutschland zögerte in Bezug auf eine militärische Attacke der Tschechoslowakei. Diese verfügt in dieser Zeit über eine 480.000 Mann starke Armee. Hitler selbst schwankt im Hinblick auf die Notwendigkeit eines militärischen Eingreifens Ungarns gegen die Tschechoslowakei. Vorsicht gab es auch auf ungarischer Seite, Furcht auf beiden Seiten vor einem europäischen Krieg wegen der realen Gefahr des Eintritts Großbritanniens in den Krieg.

Am 29. Juni 1939 führte Ministerpräsident Milan Hodža (1878-1944) in Prag mit den führenden Vertretern der Vereinigten Ungarischen Partei (ungarisch: Egyesült Magyar Párt) in Hinblick auf den künftigen Status der ungarischen Minderheit in der Tschechoslowakei Gespräche. Die Vertreter der Vereinigten Ungarischen Partei fordern die Realisierung der Autonomie bzw. des Autonomie-Status der ungarischen Minderheit innerhalb der Tschechoslowakei.

Die kleine Entente löst sich auf der Konferenz, die Anfang Mai 1938 in Sinaia (Rumänien) stattfindet, wegen der Meinungsunterschiede in der Beurteilung der Minderheitenfrage im Hinblick auf die ungarische Minderheit, die in den drei Mitgliedstaaten der kleinen Entente lebt, auf. Diese nehmen den mit Nachdruck geäußerten Wunsch der ungarischen Regierung an, Verhandlungen über die Minderheitenfrage separat, d.h. mit Prag, Bukarest und Belgrad, autonom in der Zukunft zu führen. Am 29. August 1938 fand das (letzte) Treffen der Mitgliedstaaten der kleinen Entente in Bled statt. Hier ist darauf zu verweisen, dass die kleine Entente nach der Auflösung der Tschechoslowakei im März 1939 (aber schon nach dem Münchener Abkommen bzw. am 5. Oktober 1938 nach dem Rücktritt von Edvard Beně̌ als Staatspräsident) de facto aufgehört hat, zu bestehen.

Auf der Konferenz in Bled erkennen die drei Mitgliedstaaten die Gleichberechtigung Ungarns in der militärischen Rüstung an. Die vier Verhandlungspartner verzichten auf die

18 Das am 14. August 1920 unterzeichnete Abkommen zwischen der Tschechoslowakei und dem SHS-Staat ist als Grundlage (völkerrechtliche Basis) der sog. kleinen Entente zu betrachten. Es folgen am 23. April 1921 das Verteidigungsabkommen zwischen der Tschechoslowakei und Rumänien, am 7. Juni 1921 das Verteidigungsabkommen zwischen Rumänien und dem SHS-Staat, im Jahre 1924 der Bündnis- und Freundschaftsvertrag zwischen Frankreich und der Tschechoslowakei. Dieser Vertrag wurde nach Locarno (1925) mit einem Garantievertrag ergänzt. Weiters folgen im Jahre 1926 der Freundschaftsvertrag zwischen Frankreich und Rumänien, im November 1927 das Freundschaftsabkommen zwischen Frankreich und dem SHS-Staat, am 27. Juni 1930 das Statut der sog. kleinen Entente. Die formelle Errichtung der sog. kleinen Entente zwischen der Tschechoslowakei, Jugoslawien und Rumänien wird in Genf am 16. Februar 1933 von den Außenministern der Mitgliedstaaten unterzeichnet und es werden der Permanente (Ständige) Rat und der Wirtschaftsrat der kleinen Entente errichtet. Am 9. Juni 1934 erkennen die Mitgliedstaaten der kleinen Entente, mit Ausnahme Jugoslawiens, die Sowjetunion an. Zwischen Jugoslawien und der Sowjetunion werden die diplomatischen Beziehungen am 25. Juni 1940 aufgenommen. Der Freundschafts- und Nichtangriffsvertrag zwischen beiden Staaten wird am 5. April 1941 unterzeichnet. 
Anwendung von Gewalt. Friedliche Beilegung der Streitfragen wird zum Ziel erklärt. Die Minderheitenerklärung seitens der Tschechoslowakei bleibt aber im „Schwebezustand“. Der offizielle Text der Vereinbarung in Bled spricht von ,übrigen "Fragen, die weiterer Verhandlungen bedürfen. Nach ungarischer Meinung hängt die Gültigkeit der ersten zwei Punkte von der Vereinbarung im dritten Punkt (sc. die Regelung der Minderheitenfrage) ab. Nach Ansicht der Vertreter der Mitgliedstaaten der kleinen Entente hingegen gelten die ersten zwei Punkte der Vereinbarung als endgültig. Dieses Abkommen trat aber nicht in Kraft, weil es nicht von dem ungarischen Parlament in beiden Kammern - Abgeordnetenhaus (ungarisch: Képviselóház) und Oberhaus (ungarisch: Felsőház) - ratifiziert wurde. Die Vereinbarung von Bled wird auch von der Tschechoslowakei - wegen der Gebietsansprüche Ungarns - nicht unterzeichnet, sondern nur paraphiert.

Die Vereinbarung von Bled fiel zeitlich, aber ohne Absicht d.h. zufällig, mit dem Anfang des fünftägigen ungarischen Staatsbesuchs auf Einladung von Reichskanzler Hitler vom 23. August bis 28. August 1938 zusammen. Aus Ungarn kamen Reichsverweser Horthy, Ministerpräsident Bela Imrédy, Kálmán Kánya, Lajos Keresztes-Fischer (Generalstabchef), Lajos Kubl (Leiter der politischen Abteilung des Außenministeriums) und Jenố Rátr. (Verteidigungsminister). Sie besuchten Berlin, Hamburg, Kiel, Nürnberg, Potsdam und Karinhall. Es kommt in Kiel zu folgendem Versuch Adolf Hitlers und der politischen Führung Deutschlands (Joachim von Ribbentrop, 1893-1946): Die militärische Attacke auf die Tschechoslowakei solle von Ungarn initiiert werden, nach dem ungarischen Angriff soll die Wehrmacht des Deutschen Reiches eingreifen und militärische Hilfe leisten. Hitler versprach als „Kompensation“ für die Mobilmachung bzw. die militärische Attacke Ungarns die mehrheitlich von Ungarn bewohnten Gebiete der Slowakei, eventuell die ganze Slowakei (Oberungarn, ungarisch: Felsőmagyarország) bis zu den Karpaten Ungarn zurückzugeben. Er forderte eine sofortige Antwort d.h. Einwilligung. Diese Idee bzw. dieser Vorschlag wird von ungarischer Seite energisch und eindeutig zurückgewiesen. Es gibt zwei Gründe dafür: Die Rücksichtnahme auf die sehr wahrscheinlich negative Beurteilung und Verurteilung Ungarns militärischer Aktion durch die Weltöffentlichkeit und die reale Angst vor der Eventualität einer militärischen Niederlage Ungarns, denn militärisch war die Tschechoslowakei Ungarn gegenüber zweifelsohne überlegen. Reichsverweser Hortby wies Hitlers Versuch energisch zurück. Selbst zu einer Mobilmachung Ungarns konnte ihn Hitler während ihres Treffens in Kiel nicht überzeugen. Horthys Standpunkt wurde von den Mitgliedern der ungarischen Delegation einhellig unterstützt. Der gleiche Standpunkt wurde anlässlich der Verhandlungen zwischen Reichsaußenminister Joachim von Ribbentrop und den Mitgliedern der ungarischen Delegation bekräftigt, auch von Lajos Keresztes Fischer während seiner Gespräche mit Keitel.

Mitte September 1938 kommt es zum Versuch von Kálmán (Koloman) Darányi (Ministerpräsident vom 10. Oktober 1936 bis 13. Mai 1938) den Konflikt zwischen Berlin und Budapest mit diplomatischen Mitteln zu schlichten bzw. beizulegen. Die Frage der Angliederung der Karpatho-Ukraine (ukrainisch bzw. slowakisch: Rusinsko bzw. Podkarpatská Rus, ungarisch: Kárpátaljai Oroszország, Kárpátalja oder Kelet-Felvidék) an Ungarn beschäftigt namhafte Politiker in der Karpatho-Ukraine: Sztepan Fencrik (auf Ungarisch: István Fencsik), Andrej Brody (ungarisch: András Bródy (1895-1946), Mihai Demko und August (Ágoston) Volosin. Andrej Brody war vom 11. Oktober bis 26. Oktober der erste Ministerpräsident der Podkarpatská Rus, die innerhalb der Tschechoslowakei nach dem Münchner Abkommen einen Autonomiestatus hatte. Später wurde 
Bródy Mitglied der Sirovy-Regierung ${ }^{19}$ und war hier für die Angelegenheiten der Podkarpatská Rus zuständig.

Erwähnenswert ist die Mission von Lord Walter Runciman in der Tschechoslowakei vom 3. August bis 16. September 1938. In dieser Periode hält er sich in erster Linie in Prag auf. In der Folge gewährt die tschechoslowakische Regierung am 18. September 1938 dem Sudetenland Autonomie. Zeitgleich besucht Oberst (Generaloberst ab 1939) Rudolf Andorka (1891-1961) Warschau am 12. September 1938, um Verhandlungen über eine gemeinsame (,konzentrierte ") politische Aktion zwischen beiden Ländern in Bezug auf die Lösung der Minderheitenfrage in der Tschechoslowakei zu führen. Danach trifft am 15. September 1938 Sir Arthur Neville Chamberlain (Ministerpräsident des Vereinigten Königreichs vom 28. Mai 1937 bis 10. Mai 1940) ${ }^{20}$ mit Hitler in Berchtesgaden (Obersalzberg) zusammen. Während dieses Treffens kommt die Frage der ungarischen Minderheit nicht ins Gespräch. Am 22. September 1938 findet das zweite Treffen zwischen Chamberlain und Hitler in Bad Godesberg statt. Die Verhandlungen enden am 23. September ohne Ergebnis.

Angeboten wird nun italienische Hilfe als Vermittlungsversuch, vorbereitet in der Presse durch einen Artikel in Giornale d'Italia, eine der offiziellen Zeitungen des Regimes in Italien. In diesen Tagen, am 16. September 1938, trifft Hermann Göring in Berlin mit Döme Sz̨ójay zusammen. Zweck des Treffens ist die Bewertung der Rolle der ungarischen Minderheit in der Tschechoslowakei, die sich - nach einhelliger Meinung - in wesentlichen Punkten von der Lage der Sudetendeutschen unterscheidet. Der Pester Lloyd, eine traditionsreiche Tageszeitung Ungarns, gegründet im Jahre 1854, schlägt am 17. September 1938 vor, es solle die Frage der ungarischen Minderheit in der Tschechoslowakei mit der Frage der sudetendeutschen zusammen gelöst werden. Am gleichen Tag erörtern György Barcza (1888-1961), der Gesandte Ungarns in London vom 25. Mai 1938 bis April 1941, Édouard Daladier (1884-1970) (Ministerpräsident zum zweiten Male in den Jahren 1938-1940) und Georges Bonnet (Außenminister), der „starke Mann“"(homme fort in der französischen Regierung), die Frage der polnischen und der ungarischen Minderheit in der Tschechoslowakei. Im Gespräch Barczas mit Edward Frederick Lindley Wood Earl of Halifax (Chef des Foreign Office von März 1938 bis Dezember 1940) am 20. September 1938 zeigt dieser Verständnis für Ungarn. Sein vorrangiges Ziel: zuerst den Frieden in Europa zu sichern. Zu dieser Zeit verhandeln in Warschau András Hóry (1886-1971), der Gesandte Ungarns in Warschau von 1936 bis 1939, und Josef Beck (1894-1944), der Außenminister Polens vom November 1932 bis Ende September 1939 (sodann Asyl in Rumänien) über das Schicksal der Karpatho-Ukraine. Ziel der Verhandlungen ist die Errichtung einer gemeinsamen Grenze zwischen Polen und Ungarn.

Am 20. September 1938 wendet sich Hortby brieflich an Hitler mit der Bitte um Unterstützung der ungarischen Minderheit in der Tschechoslowakei. Auch kommt es an diesem Tag zum Besuch von Ministerpräsident Béla Imrédy, Kálmán Kánya und Lajos Keresżtes Fischer bei

\footnotetext{
19 András Bródy studierte Jura in Budapest. Er war Mitglied der slowakischen Delegation bei den Verhandlungen in Komárom. Er setzte sich für friedliche Lösung des Konflikts zwischen Ungarn und der Tschechoslowakei ein und für die Schlichtung der Grenzfrage durch Volksentscheid. Er wurde im Herbst 1938 inhaftiert und erst am 11. Februar 1939 freigelassen. Im März 1939 kehrte Bródy nach Ungvár zurück und wurde Abgeordneter im ungarischen Parlament. Am 25. November 1945 wurde er durch die NKWD inhaftiert und im Mai 1946 durch das Volksgericht in Ungvár wegen Kollaboration mit Ungarn (mit dem Horthy-Regime) zum Tode verurteilt wie auch Mibai Demko und István Fencsik. Das Todesurteil wurde am 11. Juni 1946 (nach einigen Angaben später, am 7. Dezember 1946) vollstreckt.

${ }^{20}$ Sir Neville Chamberlain starb am 9. November 1940.
} 
Hitler am Obersalzberg; anwesend sind auch Ribbentrop und Keitel. Hitler wiederholt seine Vorschläge von Kiel. Er hat nicht die Absicht, in München die ungarischen Gebietsansprüche zu unterstützen. Ungarn hätte das Risiko eines militärischen Eingreifens annehmen müssen.

Rumänien und Jugoslawien halten die Angliederung des mehrheitlich von Ungarn bewohnten südlichen Streifens der Slowakei an Ungarn für möglich. Wichtig wird am 22. September 1938 die Note von Außenminister Galeazzo Ciano an Großbritannien: Die Nationalitätenfrage in der Tschechoslowakei sei in ihrer Gesamtheit (Sudetendeutsche, Ungarn und Polen) zu lösen. Die Situation der Ruthenen in der Karpatho-Ukraine wird nicht erörtert. Benito Mussolini hält vier wichtige Reden: am 18. September 1938 in Triest, am 21. September 1938 in Treviso, am 24. September 1938 in Padua und am 26. September 1938 in Verona. Eindeutig tritt Mussolini für Ungarn ein: politische Unterstützung der ungarischen territorialen Revisionsansprüche der Tschechoslowakei gegenüber. Polen und Ungarn wollen mit friedlichen Mitteln auftreten bzw. Druck auf die Regierung von Prag ausüben. Die europäischen Großmächte (Vereinigtes Königreich, Frankreich, Deutschland und Italien) unterstützen die territorialen Forderungen (Ansprüche) beider Länder.

Am 26. September 1938 hält Hitler eine Rede in Berlin (im Sportpalast), in der er auf alle territorialen Ansprüche Deutschlands, mit Ausnahme der sudetendeutschen Gebiete, verzichtet. Diese Rede beruhigt Polen. Es kommt zu - erfolglosen - Verhandlungen unter Edvard Benes, Kamil Krofta (1876-1945, Historiker, Diplomat, Politiker, Stellvertretender Außenminister der Tschechoslowakei in den Jahren 1927-1935, Außenminister in den Jahren 1935-1938) - und Ignacy Moscicki, Staatspräsident Polens vom 4. Juni 1926 bis Ende September 1939, über die Übergabe von Teilen von Schlesien (Olsa-Gebiet, auf Polnisch: Zaolzie, auf Tschechisch: Zaolśi oder Zaolźi) an Polen. Am 28. September 1938 ist es Döme Sztójay (Gesandter Ungarns in Berlin) gelungen, Kontakt mit Hermann Göring aufzunehmen. Dieses Treffen hat keinen Erfolg - die ungarische Frage bleibt weiterhin offen d.h. ungelöst. Am 29. September 1938 versichern Mussolini und Ciano Graf István Csáky (1894-1941) (Chef de cabinet im ungarischen Außenministerium in den Jahren 1936-1938, vom 10. Dezember 1938 bis zum am 26. Januar 1941 erfolgten Tode Außenminister) bei den Verhandlungen in München die ungarischen Gebietsanforderungen - auf ethnischer Basis - zu unterstützen. Das historische Prinzip - die Slowakei als Oberungarn (ungarisch: Felsőmagyarország), d.h. als Bestandteil der Länder der Stephanskrone zu verstehen - wird von Italien abgelehnt.

Hitler wollte aber selbst (ohne ,fremde Einmischung ") die polnische und ungarische Frage (d.h. Gebietsanforderungen beider Länder in Bezug auf die Tschechoslowakei) regeln. Gemäß Telegramm von Lord Halifax am Abend 29. September solle die tschechoslowakische Regierung unter allen Umständen dazu veranlasst werden, diejenigen Gebiete an Ungarn abzutreten, die mehrheitlich von Ungarn bewohnt sind (,im Einvernehmen mit dem ethnischen Prinzip").

Sir Arthur Neville Chamberlain (1869-1940, Premierminister von 1937 bis 1940) und Daladier beeilen sich nun, mit Hitler ein Abkommen zu schließen, ohne Rücksicht auf die Gebietsanforderungen (bzw. Ansprüche) von Polen und Ungarn zu nehmen. Hier verweisen wir darauf, dass Chamberlain am 22. September 1938 während seines zweiten Treffens mit Hitler auch die Möglichkeit bzw. Notwendigkeit der ungarischen Ansprüche zur Sprache brachte.

Maßgeblich ist der Einfluss von Mussolini. Die Sowjetunion - als „arbiter" bzw. „Schiedsrichter" - wird nicht nach München eingeladen. Die Folge: die Sowjetunion ist keine 
Signatarmacht des Münchener Abkommens. Diese Entscheidung von den vier Signatarmächten wird von Moskau sehr negativ, mit großer „Enttäuschung“ d.h. Befremden betrachtet bzw. bewertet. Das Münchener Abkommen wurde später zum Inbegriff der Appeasement-Politik der britischen Regierung unter Sir Neville Chamberlain und war gleichzeitig eine Art Symbol für politische (außenpolitische) Fehleinschätzung und Kapitulation.

\section{Die politischen Ereignisse nach dem Münchener Abkommen vom 30. September 1938}

Im Protokoll des Münchener Abkommens sind die polnischen und die ungarischen Gebietsansprüche nur im Anhang (Appendix) erwähnt. Als Frist für die Lösung der Streitfragen waren drei Monate ab der Unterzeichnung des Abkommens vorgesehen.

In der Nacht zum 30. September 1938 richtet die polnische Regierung ein Ultimatum an Prag, in dem Warschau den bereits verkündeten Anschluss des Teschen-Gebiets (Olsagebiet) gebietsmäßig $221 \mathrm{~km}^{2}$ - an Polen fordert. Die tschechoslowakische Regierung lenkt unter militärischem Druck ein. Dieses Gebiet wird am 2. Oktober 1938 laut einer Sondervereinbarung zwischen Prag und Warschau an Polen übergeben. In der britischen Presse ist von „Leichenfledderei“ die Rede. Berlin erhebt keine Einwände. Der NS-Staat schaltet sich nicht in die Beziehungen zwischen Polen und der Tschechoslowakei ein. Einer Intervention enthalten sich auch Frankreich, Großbritannien und Italien, d.h. die anderen Signatarmächte des Münchener Abkommens.

In Budapest findet am 1. Oktober 1938 eine Regierungssitzung statt: Der Wunsch nach einer möglichst schnellen politischen Lösung und das Beharren auf dem Selbstbestimmungsrecht der ungarischen Minderheit in der Tschechoslowakei werden festgehalten. Außenminister Kamil Krofta ist bereit zur Verhandlung. Nach Meinung von Jan Masaryk (1886-1948, Botschafter der Tschechoslowakei in London 1925-1938) ist jedoch keine Eile erforderlich. Sir Geoffrey George Knox (1884-1958), der britische Gesandte in Budapest vom Oktober 1935 bis 16. Mai 1939, zwischen 1932 und 1935 Präsident der Regierenden Kommission des Saarlandes in Saarbrücken, ermahnt in belehrendem Ton den Außenminister Kálmán Kánya bzw. die ungarische Regierung zur Zurückhaltung in Bezug auf die Gebietsforderungen der Tschechoslowakei. Die gleiche Position nimmt er in der Frage der Angliederung der Karpatho-Ukraine an Ungarn ein. Die ironische Antwort von Kálmán Kánya: „His Majesty's Government würde in Berlin den gleichen Rat geben “ - in Anspielung auf Neville Chamberlain's Vermittlungsversuche am Obersalzberg und in Bad Godesberg. Der Nachfolger von Knox wird Sir Owen St. Clair O'Malley (1887-1974), der bis 1941 in Budapest bleibt.

General Jan Syrovy (1888-1970), Hauptinspektor der tschechoslowakischen Armee, wird der neue tschechoslowakische Ministerpräsident vom 23. September bis 1. Dezember 1938 als Nachfolger von Milan Hodža (im Exil in London). Syrovy nimmt provisorisch nach der Abdankung von Edvard Beneš am 5. Oktober 1938 verfassungsmäßig auch die Funktion des Staatsoberhauptes bis 30. November 1938, den Tag der Wahl von Emil Hácha (1872-1945) zum Präsidenten, wahr. Bis 27. April 1939 hat er auch den Geschäftsbereich des Verteidigungsministers inne. Die erste Regierung Syrovy dauert bis 5. Oktober 1938. Edvard Beně̌ verlässt inzwischen - am 22. Oktober 1938 - die Tschechoslowakei. Er geht ins Exil nach England und lässt sich in London nieder. In der ersten Regierung Syroyy hat Kamil Krofta den Geschäftsbereich des Außenministers inne. In der 
zweiten Regierung Syrovy wird Ferdinand Chvalkovský, der früher Gesandter der Tschechoslowakei am Quirinal in Rom war, Außenminister. Nachfolger Syrovys als Ministerpräsident wird am 1. Dezember 1938 Rudolf Beran, der vom Staatspräsident Emil Hácha ernannt wird. Beran nimmt das Amt des Ministerpräsidenten bis 27. April 1939 wahr.

In Rom besucht Baron Frigyes Villani (1992-1964), Gesandter Ungarns in Rom am Quirinal, Benito Mussolini und führt Gespräche mit ihm. Auf Einladung von Józef Beck (polnischer Außenminister von 1932 bis 1939) kommt es zum Besuch von Graf István Csáky in Warschau am 5./6. Oktober 1938. Die nicht zu unterschätzende Folge des Besuches von Csáky war eine enge bzw. engere politische Kooperation zwischen Polen und Ungarn. Der britische Gesandte Knox schreibt am 8. Oktober 1938 von ,der kleinen Budapest-Warschau Achse“ als Ergebnis des Besuches von Graf István Csáky in Warschau.

Am 6. Oktober 1938 erfolgt in Zilina (ungarisch: Zsolna) in einem Manifest die Proklamation der Autonomie der Slowakei (ungarisch: Zsolnai manifesztum). Die Erklärung der Autonomie wird bei der Sitzung der Slowakischen Volkspartei (HSL'S) von Andrzej Hink $a^{21}$ verkündet, woran auch die Vertreter der anderen slowakischen politischen Parteien teilnehmen. ${ }^{22}$ Zum Vorsitzenden der autonomen slowakischen Regierung wird am 7. Oktober 1938 Prälat Jozef Tiso gewählt. In diesen Tagen findet in Prag eine ernsthafte Regierungskrise statt. János Wettstein (Gesandter von Ungarn in Prag) veranlasst am 8. Oktober die Wiederaufnahme der Verhandlungen zwischen Ungarn und der Tschechoslowakei. Mitglieder der tschechoslowakischen Delegation sind: Ivan Krno (1891-1968), Stellvertretender Ministerpräsident; Jozef Tiso; Ferdinand Duř́anský (1906-1974, Juraprofessor, Völkerrechtler, einer der Führer der Slowakischen Volkspartei, ab Oktober 1938 zunächst Justizminister, später Gesundheitsminister in der autonomen slowakischen Regierung und in den Jahren 1939-1940 Außenminister der slowakischen Regierung); General Viest Parkanij als Vertreter der Zentralregierung in Prag und Minister für die Karpatho-Ukraine.

Hier sei darauf verwiesen, dass Edmund Bacsins₹ky-Bacinsky (1880-1945) ab 8. Oktober 1938 die Funktion des Innenministers der autonomen Regierung der Karpatho-Ukraine wahrnahm. Mitglieder der ungarischen Delegation sind: Kálmán Kánya als Leiter der Delegation; Pál Teleki, Minister für Kultus und Unterricht; Tibor Pataky (1889-?), ab 1938 Staatssekretär im Amt des Ministerpräsidenten, zuständig für Minderheitenfragen (ohne eigenen Geschäftsbereich bzw. Ressort); Tibor Péchy, Staatssekretär; János Wettstein, außerordentlicher Gesandter und bevollmächtigter Minister; Lajos Kubl, Botschaftsrat, Pál Sebestyén, Ministerialrat, und Rudolf Andork, , Oberst im Generalstab.

Die tschechoslowakische Verhandlungsdelegation besteht ausschließlich aus Slowaken. Leiter der Delegation ist Josef Tiso, der vor zwei Tagen zum Ministerpräsidenten der autonomen

21 Der katholische Priester und Politiker Andrzej Hlinka (1864-1938) gründete im Jahre 1913 die Slowakische Volkspartei, die aber erst im Jahre 1925 diesen Namen aufnahm. Die Slowakische Volkspartei, die auch im tschechoslowakischen Parlament in Prag vertreten war, setzte sich für die Autonomie der Slowakei ein. Hlinka und die Slowakische Volkspartei beriefen sich auf die Deklaration in Pittsburgh (US-Bundesstaat Pennsylvania) am 31. Mai 1918, die die Autonomie der Slowakei vorsah. Andrzej Hlinka starb am 16. August 1938 d.h. vor der Erklärung der Autonomie der Slowakei.

${ }^{22}$ Die Erklärung der Autonomie d.h. nicht die Unabhängigkeit der Slowakei in Zilina (ungarisch: Zsolna) wird in Prag mit Erleichterung angenommen. Dadurch wird nämlich das Fortbestehen des tschechoslowakischen Staates gesichert. 
slowakischen Regierung ernannt wurde. Die tschechoslowakische Delegation hatte keine Experten unter ihren Mitgliedern.

Voraussetzung der bilateralen Verhandlungen zwischen Ungarn und der Tschechoslowakei auf ungarischer Seite: Übergabe (Rückgliederung) entweder von Révkomárom (slowakisch: Komarno) oder Ipolyság (slowakisch: Sahy) oder Párkány (slowakisch: Sturovo) an Ungarn als symbolischer Akt (Zeichen) des ,guten Willens" bzw. der Bereitschaft zur „seriösen “ und friedlichen Beilegung des Konflikts zwischen beiden Ländern seitens des tschechoslowakischen Verhandlungspartners. Statt Révkomárom und Párkány werden Bahnhof und Industriebereich von Sátoraljaújhely an der Staatsgrenze bei dem nicht schiffbaren Fluss Ronyva am 9. Oktober und Ipolyság am 11. Oktober Ungarn übergeben, die ungarische Landwehr (ungarisch: honvédség) besetzt beide Ortschaften. Am 9. Oktober 1938 am Abend um 19 Uhr beginnen die Verhandlungen in Komárom (Révkomárom; slowakisch: Komarno, deutsch: Komorn) im alten Komitatshaus (ungarisch vármegyeháza). Die Verhandlungen dauern vier Tage und enden am 13. Oktober um 19.10 Uhr mit Abbruch, d.h. ohne Ergebnis! Der Konflikt bleibt weiterhin ungelöst. Die Verhandlungen dienen nur teilweise zur Klärung der weitgehend unterschiedlichen Meinungen. Ergebnis der Verhandlungen: die slowakischen Verhandlungspartner erkennen die Gebietsansprüche Ungarns an. Sie sind bereit, den Ungarn innerhalb der Tschechoslowakei nicht nur Autonomie zu gewähren.

Ministerpräsidenten Syrovy und Außenminister Chvalkovský wenden sich an Berlin, Rom, London, Warschau und Paris, nicht aber an Moskau. Die Sowjetunion bleibt weiterhin von der Teilnahme an der Schlichtung der Krise ausgeschlossen. Die Folge: Verstimmung in Moskau.

Es folgt der Besuch von Kálmán Darányi am 14. Oktober am Obersalzberg (Berchtesgaden) bei Hitler. Am Gespräch nimmt auch Joachim von Ribbentrop teil. Darányi trägt vor, dass Ungarn bereit ist, aus dem Völkerbund auszutreten und dem Antikominternpakt ${ }^{23}$ beizutreten. Außerdem ist Ungarn bereit, mit dem Deutschen Reich ein für dieses vorteilhafte Wirtschaftsabkommen für zehn Jahre zu schließen. Das Protokoll führt Botschaftsrat im Auswärtigen Amt Hewell. Am Abend des gleichen Tages findet ein Treffen zwischen Darányi und Ribbentrop - Edmund Veesenmeyer (1904-1977), der später Reichsbeauftragte in Ungarn wurde, ist auch anwesend - in München statt. Ribbentrop ist mit der Errichtung einer neuen Grenze zwischen Ungarn und der Slowakei nach dem ethnischen Prinzip einverstanden. Ribbentrop trägt die Idee der Errichtung eines unabhängigen Rusinsko (Karpatho-Ukraine) unter deutschem Protektorat vor. Er spricht aber nicht über die Details dieses Planes. Darányi kehrt am nächsten Tag, am 15. Oktober, nach Budapest zurück. Am gleichen Tag, am 14. Oktober 1938, findet in Rom das Treffen zwischen Graf István Csáky, Mussolini und Ciano statt, an dem auch der ungarische Gesandte Baron Villani teilnimmt. Graf Csáky trägt Mussolini und Ciano den Vorschlag zur Lösung des zwischen Ungarn und der Tschechoslowakei bestehenden Konflikts, der aus sieben Punkten besteht und von Ministerpräsident Béla Imrédy vorbereitet wurde, vor.

Der Text des Vorschlages ist nicht erhalten geblieben, kann jedoch aus dem Text bzw. aus der Zusammenfassung von Mussolinis Vorschlägen rekonstruiert werden. Nach Mussolinis Meinung soll der Konflikt durch ein zweites Viermächteabkommen beigelegt werden. Die Konferenz der

\footnotetext{
23 Der Antikominternpakt wurde am 25. November 1936 zwischen Deutschland und Japan in Berlin unterzeichnet. Italien trat dem Antikominternpakt in am 6. November 1937 bei, Spanien am 7. April 1939. Dem Pakt traten insgesamt 13 Staaten bei.
} 
vier Signatarmächte soll in Genua stattfinden. Mussolini verspricht außerdem militärische Hilfe. Ciano gibt noch am Nachmittag des gleichen Tages, ohne Berlin zu fragen, die Weisung an die Gesandten bzw. Botschafter Italiens in Berlin, London, Paris und Beograd, die diplomatische Note Ungarns, in der eine Konferenz der vier Mächte in Venedig oder in Brioni vorgeschlagen wird, zu übergeben. Darüber informiert Ciano auch die in Rom akkreditierten Botschafter von England, Jugoslawien und Polen. Lord Perth, der Botschafter des Vereinigten Königreichs am Quirinal, drängt in London auf die Annahme des Vorschlags von Ciano.

Am 20. Oktober bittet Kálmán Kánya Ciano um Hilfe. Kánya verweist darauf, dass der (dritte) tschechoslowakische Vorschlag die Rückgabe von fünf größeren Städten, Pozsony, Nyitra, Kassa, Munkács und Ungvár und zwei kleineren Städten, Léva und Rimaszombat, nicht vorsieht. Der Vorschlag ist deswegen für Budapest nicht akzeptabel. Prag ist bereit, 11.300 Quadratkilometer Gebiet zugunsten Ungarns abzutreten. ${ }^{24}$ Ciano soll bei Joachim von Ribbentrop intervenieren. Kánya weist darauf hin, dass Ungarn bereit ist, einen Schiedsspruch von Deutschland und Italien zu akzeptieren. Er betont, dass Budapest in der Frage der KarpathoUkraine auch mit der Teilnahme Polens am Schiedsspruch rechnet.

In Berlin finden am 24. Oktober 1938 zwischen Joachim von Ribbentrop und dem polnischen Gesandten, Josef Lipski (1894-1958, von 1934 bis 1939 Botschafter Polens in Berlin, ab 1945 im Exil) Verhandlungen statt. Die Reichsregierung schlug vor, mit Polen in Bezug auf den Status des Freistaates Danzig (Gdansk) und den Korridor zu verhandeln. Der Ton ist (noch!) friedlich. Die Kooperation zwischen Deutschland und Polen basiert auf dem deutsch-polnischen Nichtangriffspakt vom 26. Januar 1934. Lipski übergibt am 30. Oktober 1938 die Antwort von Warschau in Form einer diplomatischen Note, in der die polnische Regierung ihre Bereitschaft erklärt, Verhandlungen über den neuen Status von Danzig zu führen. Das zwischen Berlin und Warschau abzuschließende Abkommen über den Status von Danzig sollte die Garantie des Völkerbundes ersetzen, die freie politische und kulturelle Entwicklung der deutschen Bevölkerung von Danzig gewährleisten und gleichzeitig die Privilegien von Polen im Hafen der Stadt sichern.

\section{Der Erste Wiener Schiedsspruch vom 2. November 1938}

Ministerpräsident Kálmán (Koloman) Darányi (1886-1939) spricht sich in München am 15. Oktober gegen kriegerische Handlungen und weitere Verhandlungen mit Prag aus. Auch kommt es zum Besuch von Ferdinand Duř̌ansky und Vojtech (Béla) Tuka (später unter anderem Ministerpräsident und Außenminister der Slowakei) bei Hermann Göring. Folge dieses Besuchs: die eindeutige politische Orientierung der führenden slowakischen Politiker an Deutschland.

Graf István Csáky trifft mit dem britischen Botschafter Perth in Rom zusammen. Dieser schlägt eventuell ein neues (zweites) Münchener Abkommen in Rom vor. Aber Hitler ist entschieden gegen ein neues (zweites) Münchener Abkommen. Die britische Presse - so die Tageszeitung The Times am 10. Oktober 1938 - ist für die Vereinigung der Karpatho-Ukraine mit Ungarn. Gegen diese Vereinigung tritt aber Moskau entschieden auf. Vladimir Petrovich Pat'omkin

\footnotetext{
24 Aufgrund des dritten tschechoslowakischen Vorschlags hätte Prag 93 Prozent des Gebietes, das dann durch den Ersten Wiener Schiedsspruch am 2. November 1938 Ungarn zugesprochen wurde, „aus freien Stücken“ übergeben. Laut ungarischem Standpunkt hätten die Schiedsrichter (Deutschland und Italien) in Wien sich nur nur über die Differenz im Hinblick auf das Territorium in ihrem Schiedsspruch beschränken sollen.
} 
(nach Aufzeichnungen von Mibály Jungerth-Arnóthy (1883-1957), Gesandter Ungarns in Moskau von 1934 bis 1939) erklärt dieses Verhalten damit, dass dies im Einklang mit dem Münchener Abkommen wäre, an dessen Zustandekommen sich die Sowjetunion - wegen des Ausbleibens der Einladung - nicht beteiligt hat: Die Sowjetunion ist keine Signatarmacht des Münchener Abkommens. Der Volkskommissar für Äußeres der Sowjetunion ist noch - von 1930 bis 1939 Maxim Maximovitsch Litwinow (1876-1951). Er wird im Jahre 1939 von Wjatscheslaw Mihailovitsch Molotow (1890-1986) abgelöst. Am 19. Oktober 1938 trifft in Galati (deutsch: Galatz, Rumänien) Jozef Beck mit Carol II. (König von Rumänien vom 8. Juni 1930 bis 6. September 1940, Tag der Abdankung, starb 1953 im Exil in Portugal) und Nicolae Petrescu-Comnen (1881-1958), dem rumänischen Außenminister (30. März 1938 - 31. Januar 1939) zusammen.

Ebenfalls am 19. Oktober 1938 vereinbaren in Berlin Joacbim von Ribbentrop, Tiso, Durčansky und Bacsinsky die Rückgabe des südlichen Streifens der Slowakei an Ungarn, jedoch ohne Pressburg (ungarisch: Pozsony, auf Slowakisch: Bratislava) und Nyitra (slowakisch: Nitra). Grundsätzlich wird das ethnische Prinzip als Basis der Regelung bzw. der Streitbeilegung angenommen ohne Rücksichtnahme auf das historische Prinzip. Beigezogen zur Verhandlung war Otto von Erdmannsdorff (1888-1978) ${ }^{25}$, Botschafter des Deutschen Reiches in Ungarn (11. Mai 1937 Juni 1941) am 20. Oktober 1938. ${ }^{26}$ Sein Nachfolger in Budapest wird Dietrich von Jagow (1892-1945). Der NSDAP-Parteimann Dietrich von Jagow ist vom 20. Juli 1941 bis März 1944 Botschafter des Deutschen Reiches in Ungarn.

Am 25. Oktober 1938 erklärt die tschechoslowakische Regierung Bereitschaft und Willen für einen Schiedsspruch (Arbitrage) mit Teilnahme von Rumänien und Polen. Außenminister in Prag ist zu dieser Zeit bereits Ferdinand Chvalkovský, dessen politische Orientierung sich von der seines Vorgängers Kamil Krofta wesentlich unterscheidet.

Am 20. Oktober 1938 erklärte in Paris der französische Außenminister Georges Bonnet (1899_ 1973), es bestehe weder Wille noch Interesse seitens Frankreichs an der Teilnahme am Schiedsspruch, d.h. an der Beilegung des Disputs zwischen Ungarn und der Tschechoslowakei. ${ }^{27}$ Am 29. Oktober 1938 findet in London ein Treffen zwischen Jan Masaryke und Lord Halifax (1881-1959) statt. Der Staatssekretär im Auswärtigen Amt von April 1938 bis 1943, ab 1943 Botschafter Deutschlands im Vatikan, Emst H. von Weizsäcker (1882-1951) trifft am 30. Oktober 1938 die Gesandten von Großbritannien und Frankreich. Zweck des Treffens ist die Verhandlung über den Schiedsspruch. Am 28. Oktober 1938 willigt die Regierung von Prag ein. Eine offene (strittige) Frage: die Zugehörigkeit von fünf wichtigen, größeren Städten, nämlich von Pozsony (Pressburg), Kassa, Munkács, Ungvár und Nyitra.

\footnotetext{
${ }_{25}$ Miklós Hortby nennt in seinen Memoiren Otto von Erdmannsdorff „den letaten Berufsdiplomat des Deutschen Reiches in Ungarn".

${ }^{26}$ Nach dem Ersten Weltkrieg diente er als Berufsdiplomat des Deutschen Reiches in Mexiko, China und Japan. Er wurde Mitglied der NSDAP erst im Jahre 1937. Nach dem Zweiten Weltkrieg wurde Otto von Erdmannsdorff in Nürnberg (Wilhelmstraßeprozess) angeklagt. Sein Prozess endete mit Freispruch. Seine Memoiren blieben unveröffentlicht. In Bezug auf die in Manuskriptform vorliegenden Befragungen von Otto von Erdmannsdorff nach dem Zweiten Weltkreig siehe: http://www.ifz-muenchen.de/archiv/zs/zs-0704.pdf. Der Nachlass von Otto von Erdmanndorff befindet sich im Politischen Archiv des Auswärtigen Amtes (http://www.auswaertigesamt.de/DE/AAmt/PolitischesArchiv/Uebersicht_node.html).

27 Georges Bonnet (Mitglied der Radikalen Partei - Parti radical) war für die Annäherung mit Deutschland in der Regierung von Edouard Daladier. Bonnet hatte mehrmals Ministerposten inne seit 1926. Daladier war vom 11. April 1938 bis 21. März Ministerpräsident (président du conseil). Sein Nachfolger wurde Paul Reynaud (vom 21. März bis 16. Juni 1940).
} 
Der Erste Wiener Schiedsspruch (französisch: Arbitrage de Vienne, englisch: Vienna Award oder Vienna Arbitration) wurde am 2. November 1938 im Oberen Belvedere, einem von Eugen von Savoyen errichteten Palais, durch Galeazzo Ciano und Joachim von Ribbentrop nach dem Scheitern der Verhandlungen zwischen Ungarn und der Tschechoslowakei in Komárom (Komarno) verkündet. ${ }^{28}$ Die tschechoslowakische und die ungarische Delegation sind anwesend. Ministerpräsident Béla Imrédy fährt nicht nach Wien. Er wird jeden Tag mehrmals telefonisch über die Verhandlungen informiert. Die tschechoslowakische Delegation besteht ausschließlich aus Slowaken. Die Zusammensetzung der Verhandlungsdelegation auf tschechoslowakischer Seite hat taktische Gründe - im Sinne der (Zentral-Regierung in Prag. Dies ist zweifelsohne als geschickter politischer und diplomatischer Schachzug seitens Prags zu bewerten.

Durch den Ersten Wiener Schiedsspruch werden gebietsmäßig $11.927 \mathrm{~km}^{2}$ Ungarn zugesprochen. Es fehlt aber eine klare Festlegung der Grenze, da die präzise Festlegung der neuen Staatsgrenze zwischen der Tschechoslowakei und Ungarn die Verhandlungen erschwert. Das Ungarn zugesprochene Gebiet wird noch in der ersten Hälfte November von ungarischen Truppen besetzt. Reichsverweser Miklós Hortby hält feierlichen Einzug zunächst am 6. November in Komárom (Révkomárom) und einige Tage später, am 11. November, in Kassa.

Der Erste Wiener Schiedsspruch als internationales Abkommen wurde durch den Gesetzesartikel 1938: XXXIV am 12. November 1938 vom ungarischen Parlament einstimmig ratifiziert. ${ }^{29}$ Die Frage der Staatsangehörigkeit wurde erst später, nach der Angliederung der Karpatho-Ukraine im März 1939 durch den Gesetzesartikel 1939: VI geregelt. Dieser Gesetzesartikel trat am 23. Juni 1939 in Kraft.

Deutschland besetzt am 11. November 1938 Pozsonyligetfalu (Preßburger Stadtwald, auf Slowakisch: Petruzalka) auf dem rechten Donauufer, einen Vorort von Pressburg, und am 21. November 1938 Dévény (Theben, Devin). Diese militärische Okkupation erfolgt ohne Einvernehmen der Slowakei bzw. der Tschecho-Slowakei. Dies führt zur Verstimmung sowohl in der Slowakei als auch in Ungarn. Vojtech (Béla) Tuka protestiert während seiner Verhandlungen mit Joachim von Ribbentrop und Hermann Göring gegen diese militärische Okkupation. Er beruft dabei sich insbesondere auf die historische und sakrale Bedeutung von Dévény als ,sakrale Kultstätte" für die Slowaken. Bei Dévény wurden nämlich von den Archäologen einige Gräber erschlossen, die bereits im Großmährischen Reich existierten. Weitere Verhandlungen folgen in Bezug auf die genaue Festlegung der Staatsgrenze. Eine gemischte slowakisch-ungarische Kommission zur Festlegung der Grenze wird etabliert. Die Arbeit dieser Kommission dauert - in der ersten Phase - bis März 1939.

\footnotetext{
28 Die Delegation des Deutschen Reiches besteht aus Joachim von Ribbentrop (Reichsaußenminister), Woermann (stellvertretender Staatssekretär), Altenburg (Botschaftsrat), Schmidt (Gesandter) und Kordt (Botschaftsrat). Die Mitglieder der italienischen Delegation sind: Galeazæo Ciano (Außenminister), Attolico (Botschafter) und Magistrati (Botschaftsrat). Die ungarische Delegation besteht aus Kálmán Kánya (Außenminister) und Pál Teleki (Minister für Kultus und Unterricht). Die Mitglieder der Delegation der Tschechoslowakei sind Chvalkovský (Außenminister) und Krno (Gesandter).

29 Die Vereinigte Ungarische Partei (auf Ungarisch: Egyesült Magyar Párt) mit 26 Abgeordneten zieht in das ungarische Parlament am 10. Juni 1939 als Oppositionspartei ein, die aber die Regierung unterstützt.
} 


\section{Die Folgen des Ersten Wiener Schiedsspruchs auf diplomatischer und politischer Ebene}

Eine schwierige innenpolitische Krise in Ungarn lässt sich schon vor dem Ersten Wiener Schiedsspruch spüren. Es gab Spannungen innerhalb der Regierungspartei, die im Parlament über die absolute Mehrheit verfügt. Die Gruppe um Sándor Sztranyavszky (1882-1942) bildet das Zentrum der Opposition. Ihr Abgeordnete László Taby (früher Gesandter Ungarns in Ankara) übt Mitte November 1938 scharfe Kritik an der Innenpolitik des Ministerpräsidenten Béla Imrédy. László Taby und seine Gruppe treten, nachdem über ihren Misstrauensantrag im Abgeordnetenhaus abgestimmt wurde, aus der Regierungspartei aus. Zwischen 16. und 23. November 1938 treten weitere 62 Abgeordnete (die sog. Dissidenten) aus der Partei der Nationalen Einheit (ungarisch: Nemzeti Egység Pártja, NEP) aus. Die von Sándor Sztranyavszky geleitete Gruppe hat die Absicht, die Regierung zum Sturz zu bringen. Am 22. November 1938 wird über die Regierung von Béla Imrédy abgestimmt - indirekt mittels Abstimmung über einen von Imrédy vorgeschlagenen (unwesentlichen) Tagesordnungsantrags. Die Abstimmung wurde auf Wunsch des Vorsitzenden des Abgeordnetenhauses, Gyula Kornis (1885-1958), dreimal wiederholt. Das Ergebnis bleibt das gleiche. Auch die Oppositionsparteien stimmen gegen die Imrédy-Regierung.

Am 23. November finden in Budapest Demonstrationen der Studenten zur Unterstützung der Imrédy-Regierung statt. Béla Imrédy hat an diesem Tag dem Reichsverweser Hortby den Rücktritt seiner Regierung angeboten. Am 28. November beauftragt Miklós Hortby wieder Béla Imrédy mit der Bildung der neuen Regierung. Horthy empfing am 26. November Pál Teleki, der während der etwa zwei Stunden lang dauernden Audienz für die Zurückweisung der Rücktrittserklärung von Béla Imrédy plädiert. Nach Ansicht von Pál Teleki könnte der Regierungswechsel die Frage der Rückgliederung der Karpatho-Ukraine negativ beeinflussen, da Imrédy das Vertrauen von Berlin hat. Zwei Tage vor der Audienz, am 24. November, versichert Reichsverweser Horthy Botschafter Erdmannsdorff, dass er nicht die Absicht hat, einen "außenpolitisch" „nicht akzeptablen" Politiker - mit anderen Worten einen für Berlin nicht akzeptablen Politiker - zum Ministerpräsidenten zu ernennen. Die Ernennung zum Ministerpräsidenten von István Bethlen käme deswegen überhaupt nicht in Frage. ${ }^{30}$ Die neue (zweite) Imrédy-Regierung wird noch am 28. November gebildet und vereidigt. Die Regierungskrise wird damit beendet.

Am 29. November 1938 bietet Kálmán Kánya aus freien Stücken seinen Rücktritt dem Ministerpräsidenten Imrédy an: er nimmt den Rücktritt von Kánya an und übernimmt provisorisch den Geschäftsbereich des Außenministers. Es gibt zwei Kandidaten für den Posten des Außenministers: Graf István Csáky, Kabinettschef (chef de cabinet) von Kálmán Kánya, und László Bárdossy, der Gesandte Ungarns in Bukarest. Graf István Csáky wird am 7. Dezember 1938 auf Vorschlag des Ministerpräsidenten Béla Imrédy vom Reichsverweser Horthy zum Außenminister ernannt. Der Kabinettschef des neuen Außenministers wird Tibor Bartheldy, der zuvor

\footnotetext{
${ }^{30}$ Hier wird darauf verwiesen, dass István Bethlen - nach Miklós Horthys Ansicht - der einzige Politiker gewesen wäre, der vielleicht eine regierungsfähige Mehrheit zusammenbringen könnte. Béla Imrédy hat seine Position bei den Deutschen auch dadurch verstärkt, dass mit seiner Erlaubnis am 26. November 1938 der nationalsozialistisch orientierte Volksbund der Deutschen in Ungarn seine konstituierende Sitzung hatten durfte.
} 
stellvertretender Leiter der Präsidialabteilung im Außenministerium war.

Am 19. November 1938 verabschiedet das Parlament in Prag das Gesetz über die Autonomie bzw. den Autonomiestatus der Slowakei und der Karpatho-Ukraine. Der offizielle Name der Tschechoslowakei wird Tschecho-Slowakei (tschechisch: Cesko-Slovensko). Am 18. Dezember finden die Parlamentswahlen in der Slowakei statt. Im slowakischen Parlament (es gibt nur eine Kammer) sind 63 Abgeordnete vertreten. Außer den Vertretern der Slowakischen Volkspartei (HSL'S) gibt es nur die Abgeordneten der Deutschen Partei, die am 10. Oktober 1938 unter der Leitung von Franz Karmasin (1901-1970) ${ }^{31}$ errichtet wurde, und der Vereinigten Ungarischen Partei unter der Leitung von János Esterbáay (1901-1957).

Außenminister Graf Istuán Csáky erklärt am 10. Dezember 1938, dass Ungarn dem Antikominternpakt beitreten wird. Der Ministerrat beschließt dies auf seiner Sitzung am 14. Januar, auch dass Ungarn in der nächsten Zukunft aus dem Völkerbund austreten wird. Anfang Januar 1939 erfährt Moskau von der Absicht Ungarns, dem Antikominternpakt beizutreten. Volkskommissar Litvinov protestiert energisch anlässlich seines Treffens mit Mibálkovics, der im Januar provisorisch in Moskau den abwesenden Gesandten Jungerth-Arnóthy vertritt. Ungarn wäre nämlich der erste Kleinstaat, der diesem Pakt beigetreten wäre. Dieser Schritt Ungarns könne eine Art Kettenreaktion auslösen und den Beitritt zum Antikominternpakt von einer Anzahl von Kleinstaaten zur Folge haben. Diese Furcht erklärt den besonders energischen Auftritt Moskaus gegen Ungarn. Ende Januar kehrt Jungerth-Arnóthy nach Moskau zurück. Der ungarische Gesandte versucht Litvinov davon zu überzeugen, dass sich Ungarns Beitritt zum Antikominternpakt nicht gegen die Sowjetunion richtet. Die Antwort von Litvinov: Ungarn habe bereits einen zu hohen Preis für die Rückgliederung eines relativ kleinen Gebiets (nämlich des südlichen Streifens der Slowakei) gezahlt und seine Handlungsfreiheit verloren. Litvinov informiert Jungerth-Arnóthy über die Entscheidung der Regierung der Sowjetunion: die Tätigkeit der diplomatischen Vertretungen in Budapest und Moskau soll eingestellt werden. Es genügt, die diplomatischen Beziehungen über Drittstaaten, in London, Paris oder Ankara, aufrechtzuerhalten.

Am 24. Februar 1939 erfolgt die Unterzeichnung des Antikominternpaktes seitens Ungarns. Als Reaktion der Sowjetunion am 2. Februar 1939 erfolgt zwar kein Abbruch der diplomatischen Beziehungen zwischen Moskau und Budapest im formalen Sinn, es findet aber eine Lockerung (détente) der Beziehungen zwischen der Sowjetunion und Ungarn statt: Die Gesandten beider Länder werden zurückberufen, die diplomatischen Beziehungen jedoch in einem dritten Land aufrechterhalten. Japan vertritt die Interessen Ungarns in Moskau. Die Wiederaufnahme der diplomatischen Beziehungen - mit Wiedererrichtung der Gesandtschaften in Budapest und in Moskau - erfolgt am 23. September 1939 nach dem Molotow-Ribbentrop-Pakt, dem deutsch-sowjetischem Nichtangriffspakt, genannt auch Stalin-Hitler-Pakt, der am 23. August 1939 in Moskau unterzeichnet wurde ${ }^{32}$, gefolgt vom deutsch-sowjetischen Grenz- und

\footnotetext{
${ }^{31}$ Fran₹ Karmasin war seit 1935 Leiter der Karpatendeutschen Partei. Später wurde er Leiter der Deutschen Partei in der Slowakei. Er war überzeugter Anhänger der NS-Ideologie und Befürworter des grenzenlosen nationalsozialistischen Einflusses. Nach dem Zweiten Weltkrieg ging er ins Exil, um einem Kriegsverbrecherprozess und der Hinrichtung zu entgehen.

${ }^{32}$ Die Wiederaufnahme der diplomatischen Beziehungen zwischen Ungarn und der Sowjetunion wird durch die vertraulichen Gespräche zwischen Mibály Jungerth-Arnóthy und Jakov Sacharovitsch Suritsch vorbereitet. Suritsch war früher Botschafter der Sowjetunion in Ankara, Berlin und in den Jahren 1937-1940 in Paris. Graf István Csáky kannte ihn persönlich. Nach dem Zweiten Weltkrieg wurde Suritsch Botschafter der Sowjetunion in Brasilien (Rio de Janeiro).
} 
Freundschaftsvertrag am 28. September 1939.

Ciano stattet im Dezember 1938 Budapest einen Staatsbesuch ab. Es wird die Möglichkeit einer engeren Kooperation zwischen Italien, Jugoslawien und Ungarn besprochen. Ciano verspricht, sich um diese Kooperation während seines Besuchs in Beograd, der im Januar 1939 stattfinden soll, zu bemühen. Tatsächlich stattet er vom 19. Januar bis 23. Januar 1939 Jugoslawien (Beograd) einen Staatsbesuch ab. Ziel seines Besuchs: die Errichtung eines Blocks, d.h. einer engeren Kooperation zwischen Italien, Jugoslawien und Ungarn. Es kommt aber zu keiner Verbesserung der Beziehungen zwischen Jugoslawien und Ungarn, Beograd beharrt darauf, dass Rumänien sein Einvernehmen erteilt. Die engere Kooperation scheitert am Konflikt wegen der territorialen Ansprüche Ungarns Rumänien gegenüber.

Vojtech (Béla) Tuka (1880-1946), Leiter des radikalen, Nazi-freundlichen Flügels der HSL'S, führt Verhandlungen mit Hitler am 12. Februar 1939. Er bittet um Hitlers Hilfe zur Errichtung des unabhängigen slowakischen Staates. Zu diesem Zweck führen am 28. Februar 1939 die führenden slowakischen Politiker Verhandlungen mit Göring.

Anfang März 1939 stellt die slowakische Regierung Forderungen an die Regierung von Prag. Am 10. März 1939 wird in der autonomen Slowakei durch die Zentral-Regierung von Prag die Militärdiktatur eingeführt. Die Regierung von Jozef Tiso wird am 10. März zur Abdankung gezwungen, er und Ferdinand Duřansky (1906-1974) von Prag ihres Regierungsamtes enthoben. Karol Sidor (1901-1953) wird der neue slowakische Ministerpräsident. Sidor wurde im Jahre 1935 ins Parlament in Prag gewählt, 1938 in der Zentralregierung von Prag Minister für slowakische Affären. Er war auch Chef der Hlinka-Garde. Am 12. März 1939 nehmen an der Sitzung der slowakischen Regierung - ohne eingeladen zu sein! - Arthur Seyss-Inquart (1892-1946) sowie Bürckel - zwei NS-Funktionäre in der seit 1938 deutschen Ostmark - und zwei deutsche Generäle teil. Sie teilen dem neuen Ministerpräsidenten Karol Sidor mit, dass es für die Slowakei möglich ist, ihre Unabhängigkeit zu erklären. Sidor weigert sich aber.

Am 13. März 1939 werden Jozef Tiso und Ferdinand Durčansky auf Anweisung Hitlers nach Berlin bestellt. Tiso führt mit Hitler und Joachim von Ribbentrop Verhandlungen. Sie geben Tiso zu verstehen, dass die Slowakei ihre Unabhängigkeit proklamieren soll. Am 14. März, nach seiner Heimkehr in Bratislava (Pressburg), informiert Tiso die Abgeordneten des slowakischen Parlaments über das Ergebnis seiner Verhandlungen in Berlin. Das slowakische Parlament proklamiert die Unabhängigkeit der Slowakei. Diese Unabhängigkeitserklärung ist die ,juristische Grundlage" des pseudo-souveränen slowakischen Staates. ${ }^{33}$ Ebenfalls am 14. März 1939 werden Emil Hácha, Präsident der Tschecho-Slowakischen Republik seit 30. November 1938, sodann Präsident des Reichsprotektorats Böhmen und Mähren ab 16. März 1939 und Chvalkovský nach Berlin bestellt. Es kommt zur Unterzeichnung - unter Druck - des Protektoratsabkommens. Zum Modell dient der Bardo-Vertrag (französisch: Traité du Bardo) vom 12. Mai 1881 zwischen Frankreich und Tunesien: Die Unterzeichnung dieses Vertrages erfolgte auf tunesischer Seite durch den Bey von Tunis.

Dies und die Unabhängigkeitserklärung der Slowakei bewirken als unmittelbare Folge die

\footnotetext{
33 Die Slowakei wurde de facto, bald auch de jure von 27 Staaten anerkannt. Unter diesen Staaten waren Deutschland, die Sowjetunion, das Vereinigte Königreich, Italien, Spanien, der Vatikan, Japan, die japanischen Satellitenstaaten Mandschukuo und Mengjian, die Provisorische Regierung von China (mit Hauptstadt in Nanking), Ungarn, die Schweiz, Kroatien, Litauen, Estland und El Salvador.
} 
Auflösung der Tschecho-Slowakischen Republik an. Ungarn erkennt am 15. März als erster Staat die Unabhängigkeit der Slowakei. Das Konsulat Ungarns in Bratislava (Pozsony) (errichtet im Jahre 1927) wird zur Gesandtschaft. Nun folgt der Einmarsch deutscher Truppen in die sog. Rest-Tschechei und die Errichtung des Reichsprotektorats Böhmen und Mähren am 16. März 1939. Sir Neville Chamberlain hält am 17. März 1939 eine Rede in Birmingham, in der er seiner Enttäuschung über die Errichtung des Reichsprotektorats Böhmen und Mähren Ausdruck gibt. Beängstigend findet er auch, dass in den Vordergrund die Frage von Danzig und des Korridors gestellt wird. Er versucht aber gleichzeitig, die Politik von Berlin zu rechtfertigen. Die Regierung von Moskau protestiert am 18. März 1938 gegen den Untergang der Tschecho-Slowakei. Darüber informiert Moskau Graf Friedrich Werner von der Schulenburg (1875-1944), den deutschen Botschafter von 1934 bis 1941 in Moskau. ${ }^{34}$

Ribbentrop bittet am 21. März Josef Lipski zu sich und wiederholt den „Vorschlag“von Hitler vom 24. Oktober 1938 in Hinblick auf Danzig und den Korridor. Der Ton ist diesmal schärfer. Am 23. März 1939 wird der „Schutzvertrag“ zwischen dem Deutschen Reich und der Slowakei unterzeichnet. Laut diesem Abkommen wird die Slowakei in Fragen der Außen- und Militärpolitik den Interessen des NS-Staates untergeordnet. Eine weitere Folge ist die Errichtung der sog. Schutzzone in der Westslowakei, die sich auf etwa 5 Prozent (ca. $2.000 \mathrm{~km}^{2}$ ) des slowakischen Staatsgebietes (ca. $39.000 \mathrm{~km}^{2}$ ) beläuft. Am gleichen Tage wird ein Abkommen über die Kooperation in Bezug auf die Wirtschafts- und Finanzpolitik zwischen beiden Staaten unterzeichnet.

Am 21. Juli 1939 wird durch das slowakische Parlament die neue Verfassung verabschiedet. Zum Modell der Verfassung dient der italienische korporative Staat (lo stato corporativo). Der offizielle Name des slowakischen Staates ist: Republik Slowakei (slowakisch: Slovenská republika). Im Hinblick auf die Nationalitätenpolitik der Slowakei ist Art. 95 der slowakischen Verfassung von Belang. Dieser Artikel geht eindeutig vom Reziprozitätsprinzip aus.

Am 4. März 1939 trifft Döme Sztójay in Berlin - auf Anweisung des Außenministers Graf István Csáky - mit Joachim von Ribbentrop zusammen. Zweck seines Besuchs: das Einvernehmen von Berlin in der Frage der Angliederung der Karpatho-Ukraine (Rusinsko) an Ungarn zu erzielen. Ribbentrop gibt aber keine definitive Antwort. Vorher führt der ungarische Militärattaché Kálmán Hardy mit Staatssekretär im Auswärtigen Amt Ernst von Weiæsäcker Verhandlungen.

Am 14. März 1939 hat übrigens Prälat August (Agoston) Volosin die Unabhängigkeit der Karpatho-Ukraine proklamiert, aber am selben Tag übergibt Außenminister Graf István Csáky ein Ultimatum an Miloš Kobr, dem Gesandten der Tschechoslowakischen Republik in Budapest (vom 20. April 1933 bis 15. März 1939), um die Karpatho-Ukraine Ungarn zurückzugeben. Trotz Deutschlands Verbot wird darüber auch Jozef Beck, der Außenminister Polens, vertraulich informiert. Am 15. März 1939 beginnt die militärische Operation Ungarns, um die KarpathoUkraine (ungarisch: Kárpátalja oder Ruténföld) Ungarn wiedereinzugliedern. Die militärische Operation (Intervention) dauert drei Tage. Als Folge bzw. Ergebnis entsteht eine gemeinsame Grenze (ungarisch: közös határ) zwischen Ungarn und Polen.

Der Grenzstreit zwischen Ungarn und der Slowakei wird ab 23. März 1939 zum

\footnotetext{
34 Graf Friedrich Werner von der Schulenburg hat Jura studiert und trat nachher in den diplomatischen Dienst. Er war Kandidat für den Posten des Ministers des Äußeren, sollte die Verschwörung vom 20. Juli 1944 gegen Hitler gelingen. Nach dem Attentat vom 20. Juli 1944 wurde er zum Tode verurteilt und hingerichtet.
} 
ernsthaften militärischen Konflikt zwischen beiden Ländern ${ }^{35}$ mit Luftkämpfen am 23. und 24. März 1939. Dieser Konflikt heißt Der kleine Krieg (ungarisch: kis háború, slowakisch: mala vojna). Berlin ermahnt Ungarn und ruft Budapest zur Einstellung der militärischen Handlungen. Der Waffenstillstand erfolgt erst am 25. März 1939. Durch die ungarische militärische Intervention wird ein Gebiet von $1.056 \mathrm{~km}^{2}$ mit 74 Ortschaften (Dörfern) an Ungarn angegliedert.

Der Zweck der ungarischen militärischen Intervention ist die Sicherung der Eisenbahnlinie im Ung-Tal. Die wichtigste von den ungarischen Truppen eroberte Siedlung ist Szobránc (Luftkrieg von Szobránc). Die Bevölkerung, etwa 40.000-45.000 Menschen auf dem angegliederten Territorium, ist mehrheitlich slowakisch und ruthenisch. Auf diesem Territorium bilden die Ungarn eine Minderheit. Die kriegerischen Handlungen beeinflussen nachhaltig negativ die slowakisch-ungarischen Beziehungen. Die neue (genaue) Staatsgrenze zwischen Ungarn und der Slowakei wird am 3. April 1939 durch die gemischte slowakisch-ungarische Grenzkommission festgelegt.

Ungarn tritt am 11. April 1939 aus dem Völkerbund (League of Nations, Société des Nations) aus. Am 6. April 1939 wurde das Abkommen über die militärische Hilfe zwischen England und Polen unterzeichnet. Am gleichen Tag wurde das französisch-polnische Abkommen bekräftigt. Am 13. April schließen das Vereinigte Königreich (United Kingdom) und Frankreich mit Griechenland und Rumänien einen Garantievertrag ab.

Das zweite sog. Judengesetz (Gesetzesartikel 1939: IV über die Beschränkung der Einflussnahme der Juden im öffentlichen und wirtschaftlichen Leben) wird am 3. März 1939 dem ungarischen Parlament (Abgeordnetenhaus und Oberhaus) vorgelegt und am 5. März verabschiedet. Dieses Gesetz trat am 5. Mai 1939 in Kraft. Von diesem Gesetz werden annähernd 500.000 Menschen sowohl im Wirtschaftsleben als auch im Hinblick auf ihre Rechte als Staatsbürger betroffen. In drei Phasen sollen bis 31. Dezember 1942 etwa 60.000 Angestellte im Wirtschaftsleben und im industriellen Bereich laut diesem Gesetz entlassen werden.

Ein umfangreicher Brief von Sir Alexander George Montagu Cadogan (1884-1968), permanent undersecretary for foreign affairs (Nachfolger von Sir Robert Gilbert Vansittart) an György Barcza in Budapest am 30. Januar 1941 stellt fest, dass das Vereinigte Königreich mit dem Ersten Wiener Schiedsspruch (First Vienna Award oder First Vienna Arbitration) nichts zu tun hat und daher diesen als Nicht-Signatarmacht nicht anerkennt.

Durch die beiden Wiener Schiedssprüche sowie die Rückgliederung der KarpathoUkraine beläuft sich der Gebietsgewinn Ungarns auf 29 Prozent der nach dem Ersten Weltkrieg abgetrennten d.h. verlorenen Gebiete.

\title{
Quellen- und Literaturverzeichnis
}

\author{
ABlOnCZY B.: Teleki Pál. Budapest 2005 \\ ÁDÁM M.: Magyarország és a kisantant a harmincas években. Budapest 1968 \\ ÁDÁM M.: A kisantant (1920-1938). Budapest 1981 \\ ÁDÁM M.: A kisantant és Európa. Budapest 1989 \\ ÁDÁM M.: Ki volt valójában Edvard Beneš? Budapest 2009 \\ ÁDÁM M.: Eduard Benes. In: Arcképek kettős tükörben. Dunaszerdahely 1997
}

\footnotetext{
${ }^{35}$ In diesen Tagen war Hitler in Berlin nicht zu erreichen, weil er sich im Memelgebiet (Litauen), das dem Deutschen Reich angegliedert wird, aufhielt.
} 
ÁDÁM M. (Hrsg.): A müncheni egyezmény létrejötte és Magyarország külpolitikája, 1936-1938. Budapest 1965

ÁDÁM M. - JuHÁSz Gy. - KEREKES L. (Ein., Vorb.): Hitler - Horthy - Mussolini. Dokumente zur ungarischen Außenpolitik 1933-1944. Budapest 1966

AJTAY J.: La paix en danger: le traité de Trianon. 14e éd. Budapest 1933

ALTENHÖFER, F.: Der Auslandsnachrichtendienst des SD und die Erklärung der slowakischen Unabhängigkeit am

14. März 1939. Zeitschrift für Geschichtswissenschaft 57/2009, 811-832.

Andorka Rudolf naplója: A madridi követségtől Mauthausenig. Budapest 1978

ARATÓ E.: A magyar-csehszlovák viszony ötven éve. Budapest 1969

ARDAY L.: Térkép, csata után. Magyarország a brit külpolitikában 1918-1919. Budapest 1990

of Austria, Otto: Danubian Reconstruction. Foreign Affairs, January 20/1942, 241-252.

BÁN D. A.: Illúziók és csalódások. Nagy-Britannia és Magyarország 1938-1941. Budapest 1998

BÁN D. A. (Hrsg.): Pax Britannica. Brit külügyi iratok a második világháború utáni Kelet-Közép Európáról 19421943. Budapest 1996

BÁNFFY M.: Huszonöt év (1945). Budapest 1993

BARTL, J:: Slovak History: Chronology and Lexicon. Bratislava 2002

BÉKÁSSY J.: Zalavármegye Trianon után. Budapest 1930

BENEŠ, E.: Le problème autrichien et la question tchèque. Paris 1908

BENEŠ, E.: Détruisiez l'Autriche Hongrie! Paris 1916

BENEŠ, E.: The Organization of Postwar Europe. Foreign Affairs, January 20/1942, 226-243.

BENEŠ, E.: Sest let exilu a druhá svetová válka. Ráci, projevy a dokumenty zr. 1938-1945. Praha 1946

BENEŠ, E.: My War Memoirs. Boston 1954

BENEŠ, E.: Mníchevské dny. Paměty. Praha 1968

BerLin, Jon D.: The Burgenland Question 1918-1920: From the Collapse of Austria-Hungary to the Treaty of Trianon. PhD Diss. University of Wisconsin at Madison 1974

Bethlen I.: The Treaty of Trianon and European Peace: Four Lectures Delivered in London in November, 1933. London 1933

Bethlen István titkos naplója. Budapest 1972

BIRINYI, L. K.: Why the Treaty of Trianon is Void. Grand Rapids 1938

BOnNET, G.: Défense de la paix. Genève 1946

BOROS F.: Magyar-csehszlokovák kapcsolatok, 1918-1921. Budapest 1970

BOTLIK J.: Ez hát a hon...Tények, adatok, dokumentumok a kárpátaljai magyarság életéből (1918-1991). Budapest Szeged 1991

BOTLIK J:: Volosin uralma Kárpátalján. Valóság 12/2000, 22-42.

Brauneder, W.: Die Republik entsteht: Österreich 1918 bis 1925. Graz 2018

BRAUNIAS, K.: Die Slowaken. Stuttgart 1942

BrausCH, G.: Deutschland-Ungarn. Die diplomatischen Beziehungen vom Herbst 1937 bis zum Frühjahr 1939. Phil. Diss. Göttingen 1956

CARr, E. H.: Conditions of Peace. London 1942

CELOvsky, B.: Das Münchener Abkommen 1938. Quellen und Darstellungen zur Zeitgeschichte, Bd. 2. Stuttgart 1958

Ceskoslovensé dejiny v datech. Praha 1986

CiERnA-LANTAYOVÁ, D.: Podoby cesko - slovensko - mad'arského vzt’ahu. 1938-1949. Bratislava 1992

CZETTLER, A.: Ungarns Weg zum ersten Wiener Schiedsspruch. Die ungarische Außenpolitik während und nach der Sudetenkrise 1938. Ungarn-Jahrbuch 16/1988, 82-156.

CZETTLER, A.: Ungarn zwischen Polen und der Achse. Die ungarisch-polnischen diplomatischen Beziehungen 1938/1939 und Józef Becks „Drittes Europa”. Ungarn-Jahrbuch 18/1990, 129-168.

CZETTLER A.: Teleki Pál és a magyar külpolitika 1939-1941. Budapest 1997

CHÁszÁr, E.: Decision in Vienna. The Czechoslovak-Hungarian Border Dispute of 1938. Astor 1978

CZAKÓ, St.: How the Hungarian Problem was Created? Some Authentic Details of the Preliminary Deliberations of the Treaty of Trianon. Budapest 1934

CZAKÓ, I.: Wie entstand der Trianoner Friedensvertrag mit Ungarn? Budapest 1934

DEAK F.: Hungary at the Paris Peace Conference: The Diplomatic History of the Treaty of Trianon. New York 1942 
DEÁK, L.: Slovensko v politike Mad'arska v rokoch 1938-1939. Bratislava 1990

DEAK, L.: Hra o Slovensko. Slovensko v politike Madarska a Polska v rokoch 1933-1939. Bratislava 1991

DEÁK, L.: Viedenská arbitraz. Bratislava 1997

DEÁK, L.: Slováci v mad'arskej politike v rokoch 1918-1939. Bratislava 1996

DeJMEK, J.: Historik v cele diplomacie. Kamil Krofta. Praha 1998

DEMETER J.: A nemzetiségi kérdés a Dunavölgyében és a Szovjetunióban. Kolozsvár 1945

Desbons, G.: La Hongrie après le Traité de Trianon. Paris 1933

Desbons, G.: Les erreurs de la paix. La Hongrie après le Traité de Trianon. Paris 1933

Die Zerstörung des Karpatenbeckens: Die Trianon-Enquete des Strassburger Kongresses der freien Ungarn. München 1970

DiÓSZEGI I.: A hatalmi politika másfél évszázada. 1789-1939. Budapest 1994

DOMBRÁDY L.: Hadsereg és politika Magyarországon 1938-1944. Budapest 1986

DOMBRÁDY L. - TóTH S.: A magyar királyi honvédség 1919-1945. Budapest 1987

DORIAN, A.: La question d'une frontière commune entre la Pologne et la Hongrie. Warszawa 1921.

DuKa ZÓLYOMI N.: Szórványmagyarok. Magyar Szemle XL/1941, 343-346.

DURČANSKÝ, F.: Pohl'ad na slovenskú politickú minulost’. Bratislava 1943

ERTL, K. H.: Die verfehlten Friedensordnungen von Versailles, Saint-Germain-en-Lay und Trianon. Rosenheim 1993

FEDINEC Cs.: A kárpátaljai magyarság történeti kronológiája 1918-1944. Galánta - Dunaszerdahely 2002

FENYŐ M.: The Trianon Treaty and Its Consequences. Budapest 1929

FERDINANDY M.: Nemzetiségi kérdés és magyar birodalom. Budapest 1942

FEST, W.: Peace or Partition. The Habsburg Monarchy and British Policy 1914-1918. New York 1978

FÜLÖP M. - SIPOS P.: Magyarország külpolitikája a XX. században. Budapest 1998

GAGYI J.: Nyugat-Magyarország átadása. Új Magyar Szemle 1921. szeptember, 280-283.

GAERTRIngen, F. Freiherr von (Hrsg.): Die Hassell-Tagebücher 1938 - 1944, Ulrich von Hassells Aufzeichnungen vom Andern Deutschland. Berlin 1994

GALÁNTAI J.: Trianon és a kisebbségvédelem. Budapest 1989

Galántai J.: Trianon the Protection of Minorities. Budapest 1992

G. KovÁcs L.: Jozef Tiso. In: Arcképek kettős tükörben. Dunaszerdahely 1997

GOGOLÁK L.: Cseh emlékiratok a békekonferencia előtt. Magyar Szemle 1938 június, 191-193.

GogOLÁK L.: Pánszlávizmus. Budapest 1940

GoszTOnYI P.: A kormányzó Horthy Miklós. Budapest 1990

GOWER, R. V.: Treaty Revision and the Hungarian Frontiers. London 1936

GULYÁS L.: Edvard Beneš - Közép-Európa koncepciók és a valóság. Budapest 2008

HANÁK P.: Jászi Oszkár dunai patriotizmusa. Budapest 1985

HARMSWORTH, H. S. Viscount Rothermere: My Campaign for Hungary. London 1939

HASAS, E.: La révision du Traité de Trianon et les difficultés suscitées. Paris 1928

HENNYEY G.: Magyarország sorsa Kelet és Nyugat között. Budapest 1992

Hillgruber, A. (Hrsg.): Deutschland und Ungarn 1933-1944. Ein Überblick über die politischen und militärischen Beziehungen im Rahmen der internationalen Politik. Wehrwissenschaftliche Rundschau 9/1959, 651-676.

Hillgruber, A.: Staatsmänner und Diplomaten bei Hitler 1939-1941. Vertrauliche Aufzeichnungen über

Unterredungen mit Vertretern des Auslandes. I: 1939-1941; II: 1942-1944. Frankfurt am Main 1967, 1970

HENNYEY, G: Ungarns Schicksal zwischen Ost und West. Lebenserinnerungen. München-Mainz 1975

Herczegh G.: A szarajevói merénylettől a potsdami konferenciáig. Budapest 1999

Hevesi A. - Kocsis K.: A magyar-szlovák határvidék földrajza. Dunaszerdahely 2003

HoDŽA, M: Federation in Central Europe. Reflections and Reminiscences. London - New York-Melbourne 1942

HoDŽA, M.: Szövetség Közép-Európában. Gondolatok és visszaemlékezések. Pozsony 2004

HoEnsch, J. K.: Die Slowakei und Hitlers Ostpolitik. Köln-Graz 1965

Hoensch, J. K.: Der ungarische Revisionismus und die Zerschlagung der Tschechoslowakei. Tübingen 1967

HoEnsch, J. K.: Nationalsozialistische Europapläne im zweiten Weltkrieg. Versuch einer Synthese. In: PLASCHKA, R. G. - Haselsteiner, H. - Suppan, A. - DrabeK, M. - ZaAr, B. (Hrsg.): Mittel-Europa-Konzeptionen in der ersten Hälfte des 20. Jahrhunderts. Wien 1995, 307-325. 
HoEnsch, J. K.: Studia Slovaca. Studien zur Geschichte der Slowakei und der Slowaken. Veröffentlichungen des Collegium Carolinum Bd. 93. München 2000

HonTI, F.: Que demande la Hongrie? Le traité de Trianon et les revendications hongroises. 2e éd. Budapest 1934 HóRY A.: Bukaresttől Varsóig. Budapest 1987

HORNYÁK, Á.: Minderheitenfrage in der Jugoslawien-Politik Ungarns. Ungarn-Jahrbuch 29/2008, 179-200. von HORTHY, N.: Ein Leben für Ungarn. Bonn 1953

HORTHY M.: Emlékirataim. Budapest 1990

Horváth Gy. (Hrsg.): Dél-Szlovákia. A kárpát-medence régiói 2. Budapest-Pécs 2004

HronskÝ, M.: The Struggle for Slovakia and the Treaty of Trianon. Bratislava 2001

HugelmanN, K. G.: Das Nationalitätenrecht des alten Österreich. Wien - Leipzig 1934

HugelmanN, K. G.: Die Vereinbarungen über die deutschen Volksgruppen in Ungarn und Rumänien in geschichtlicher Beleuchtung. Zeitschrift für Osteuropäisches Recht 1941, 235-277.

IORGA, N.: Réponse aux conférences données à Cambridge par le comte Bethlen sur la révision du traité de Trianon. Bucharest 1933

IORGA, N.: Seconde réponse au comte Bethlen. Bucharest 1933

Ítél a történelem. Az Imrédy-per. Budapest 1946

JACOBSEN, H. A.: Nationalsozialistische deutsche Außenpolitik 1933-1938. Frankfurt am Main-Berlin 1968

JacobSen, H. A.: Der Weg zur Teilung der Welt. Politik und Strategie 1939-1945. Koblenz - Bonn 1977

JANEK I.: Szlovák-magyar kapcsolatok 1939-1944. Diss. Pécs 2009

JANICS, K.: The Hungarians of Slovakia: From Czechoslovak to Slovak Rule. In: The Hungarians: A Divided Nation. New Haven 1988, 159-190.

JÁszi O.: A nemzeti államok kialakulása és a nemzetiségi kérdés. Budapest 1912

JEHLICKA, F.: Il problema slovacco. Rassegna di Politica Internazionale. Giugno 1934

JEHLICKA, F.: Le problème slovaque. Genève 1935

JuHÁsz Gy:: A Teleki-kormány külpolitikája, 1939-1941. Budapest 1964

JUHÁsz M. GY.: Hungarian Foreign Policy 1919-1945. Budapest 1979

JUHÁsz Gy.: Magyarország külpolitikája. 1919-1945. Budapest 1988

JUNGERTH-ARNÓTHY M.: Moszkvai napló. Budapest 1989

KÁDÁR Gy.: A Ludovikától Sopronkőhidáig. Budapest 1978

KAMANEC, I.: Trauma. Az első szlovák köztársaság (1939-1945). Budapest 1945

KAMENEC I.: Jozef Tiso. In: Arcképek kettős tükörben. Dunaszerdahely 1997

KÁSZONYI F.: Magyar-szlovák vérközösség. Budapest 1942

KAISER, J.: Die Politik des Dritten Reiches gegenüber der Slowakei 1939-1945. Ein Beitrag zur Erforschung der nationalsozialistischen Satellitenpolitik. Diss. Bochum 1969

KENDE P.: Le défi hongrois. De Trianon à Bruxelles. Paris 2004

KENT, B.: The Spoils of War. The Politics, Economics, and Diplomay of Reparations 1918-1932. Oxford 1989

KEREKES L.: Ausztria története, 1918-1955. Budapest 1966

KEREKES L.: A Habsburg restaurációs kísérletek és az osztrák-magyar viszony 1921-ben. Századok 1976, 38 ff.

KerTESZ, St. D.: Diplomacy in a Whirlpool. Hungary between Nazi Germany and Soviet Russia. Notre Dame, Indiana 1953

Kertész, St. D.: The Last European Peace Conference, Paris 1946. University Press of America 1985

KERTESZ, St. D.: Between Russia and the West. Hungary and the Illusions of Peacemaking 1945-1947. Buffalo NY 1992

KIMMINICH, O.: Stellungnahmen zum Münchener Abkommen in der deutschen Presse. München 1966

KIMMINICH, O: Das Münchener Abkommen. München 1968

KIRSCHBAUM, J. M.: Slovakia: Nation at the Crossroads of Central Europe. New York 1960

KIS A.: Magyarország külpolitikája a második világháború előestéjén. Budapest 1963

KOLB, E.: Der Frieden von Versailles. München 2005

KOLONTÁRI A.: Magyar-szovjet diplomáciai, politikai kapcsolatok 1920-1941. Budapest 2009

KovÁcs E.: Trianon, 1920: Párizs, 1947. Toronto 1986

KOvÁCS-BERTRAND, A.: Der ungarische Revisionismus nach dem Ersten Weltkrieg: der publizistische Kampf gegen den Frieden von Trianon (1918-1931). München 1997 
KovÁC, D.: Szlovákia története. Pozsony 2001

KozMA M.: Az összeomlás, 1918-1919. Budapest 1933

KRATOCHWIL K.: Erdélyt visza! Budapest 1939

KroftA, K.: The Substance of Hungarian Revisionism. Prague 1934

KroftA, K.: The Substance of Hungarian Revisionism. Prague 1936

KRÜGER, P.: Versailles - Deutsche Außenpolitik zwischen Revisionismus und Friedenssicherung. München 1986

KRUMEICH, G. (Hrsg.): Versailles. Ziele - Wirkung - Wahrnehmung. Essen 2001

KÜHL, J.: Föderationspläne im Donauraum und in Ostmitteleuropa. München 1958

LAKY D.: Csonka-Magyarország megszállásának közgazdasági kárai. Budapest 1923

LANSING, R.: Die Versailler Friedensverhandlungen. Berlin 1921

LAPSCHER, L.: Die mitteleuropäische Konzeption Milan Hodžas. Bohemia. A Journal of History and Civilisation in East and Central Europe. 24/1983, 299-316.

LEHÁR, A: Erinnerungen. Wien 1973

LETTRICH, J.: History of Modern Slovakia. New York 1955

LIPSKI, J.: Diplomat in Berlin, 1933-1939. New York 1968

LIPTÁK, L.: Slovensko v 20. storoči. Bratislava 1998

LUKÁCs GY:: Après Trianon: discours tenus à des conférences internationales. Budapest 1927

LUKES: Czechoslovakia between Stalin and Hitler. The Diplomacy of Eduard Benes in the 1930s. Oxford 1996

Macartney, C. A.: Problems of the Danube Basin. Cambridge 1942

MACARTNEY, C. A.: October fifteenth. A History of modern Hungary 1929-1945. vols. I-II. Edinburgh 1956

(Second ed.: Edinburgh 1996)

MAckintosh, J.: The British Cabinet. London 1962

MACŮREK, J.: Dejiny mad'aru a uherského státu. Praha 1934

Major, M. I.: American-Hungarian Relations 1918-1944. PhD diss. Texas Christian University 1972

MAKRA Z.: Honvédelmi miniszterek szolgálatában. Végzetes döntések korszaka 1940-1944. München 1986

MARTIN, B.: Friedensiniziativen und Machtpolitik im Zweiten Weltkrieg 1939-1942. Düsseldorf 1976

MATiĆ, I.: Edmund Veesenmayer. Agent und Diplomat der nationalsozialistischen Expansionspolitik. München 2002

Matolay G.: Gróf Teleki Pál élete és munkássága a magyar revízió szolgálatában. Budapest 1941

MEZEI I.: Városok Szlovákiában és a magyar határ mentén. Somorja - Pécs 2008

MichalKA, W.: Ribbentrop und die deutsche Weltpolitik 1933-1940. München 1980

MoscA, R: Problemi politici: l'Ungheria contemporanea. Bologna 1928

Montgomery, J. F.: Hungary: the Unwilling Satellite. New York 1947

Montgomery, J. F.: Magyarország, a vonakodó csatlós. Budapest 1993

MÚDRY, M: Milan Hodža v Amerike. Chicago 1949

de NAgY, E.: Le Traité de Trianon et ses conséquences. Budapest 1927

NAGY V.: Végzetes esztendők. Budapest 1986

NeBELIN, M.: Deutsche Ungarnpolitik 1939-1941. Opladen 1989

NeWManN, B.: The New Europe. London 1942

NiCOLSON, H.: Peacemaking 1919. London 1919

OpITZ, R. (Hrsg.): Europastrategien des deutschen Kapitals 1900-1945. Köln 1977

ORMOS M.: Franciaország és a keleti biztonság. Budapest 1969

Ormos M.: Padovától Trianonig. Budapest 1983

Ormos M.: „Civitas fidelissima“. Népszavazás Sopronban 1921. Budapest 1990

Ormos, M.: From Padua to the Trianon, 1918-1920. Budapest 1990

ORMOS M.: Magyarország a két világháború korában. Debrecen 1998

de Otero, L.: La théorie des traités de paix et le Traité de Trianon. Paris 1933

PALOTÁs Z.: A trianoni határok. Budapest 1990

Páter Zadravecz titkos naplója. Budapest 1967

PEÉRY R.: Requiem egy országrészért. Pozsony 1993

PÉTER J.: A magyar-szovjet diplomáciai kapcsolatok történetéből. Budapest 1979

PICHEGGER, H.: Geschichte der Steiermark. Graz 1976

POLAKOVIČ, S: Slovensky národny socializmus. Bratislava 1941 
PÖLÖSKEI F.: Horthy és hatalmi rendszere. Budapest 1977

POPÉLY Gy.: A felvidéki sorsforduló, Etnikum, impériumváltozás, országhatár. Regio - Kisebbségvédelmi Szemle 1/1990

PopéLY Gy.: A müncheni döntéstől a komáromi tárgyalások megszakadásáig. Magyar Szemle 2/1993, 1133-1150.

PopéLY Gy.: Népfogyatkozás. A csehszlovákia magyarság a népszámlálások tükrében 1918-1945. Regio Kisebbségtudományi Szemle 2/1991

PRITZ P.: Magyarország külpolitikája Gömbös Gyula miniszterelnöksége idején 1932-1936. Budapest 1982

PRITZ P: Barcza György visszaadja a „kölcsönt” Bárdossy Lászlónak. In: GEBEI S. - ifj. BERTÉNYI I. - RAINER M. J. (Hrsg.): Tanulmányok a 60 éves Romsics Ignác tiszteletére. Eger 2011, 248-254.

PRITZ P.: Magyar diplomácia a két világháború között. Budapest 1995

PRITZ P.: Pax Germanica. Német elképzelések Európa jövőjéről a második világháborúban. Budapest 1999

PRITZ P. (Hrsg.): Iratok a magyar külügyi szolgálat történetéhez 1918-1945. Budapest 1994

RÁNKI Gy.: Gazdaság és külpolitika. A nagyhatalmak harca a délkelet-európai gazdasági hegemóniáért (1919-1939). Budapest 1981

RÁNKi Gy. - PAMLÉNYI E. - Tilkovszky L. - JuHÁsz Gy. (Einf. und Hrsg.): A Wilhelmstrasse és Magyarország. Német diplomáciai iratok Magyarországról 1933-1944. Budapest 1968

RÁNKI Gy. (gesammelt, eingeführt und mit Anmerkungen ergänzt von): Hitler hatvannyolc tárgyalása 1939-1944. 12. k. Budapest 1973

RÉTi Gy. (Hrsg.): A Palazzo Chigi és Magyarország. Olasz diplomáciai dokumentumok Magyarországról 1932-1936. Budapest 2003

RÉVAY I.: Nemzetiségi demográfia és kisebbségünk. Kisebbségi problémák. Levice 1937, 40-42. RÉVAY I.: A demográfia tükrében. In: BORSODY I. (red.) Magyarok Csehszlovákiában 1918-1938. Budapest 1938

RÉVAY I.: A belvederei magyar-szlovák határ. Budapest 1941

RoMsiCs I.: Magyarország helye a német Délkelet-Európa-politikában, 1919-1944. In: RoMSICS I.: Helyünk és sorsunk a Duna-medencében. Budapest 1966, 210-233.

RoMsiCs I. (Hrsg.): Magyarország és a nagyhatalmak a XX. században. Budapest 1995

ROMSICS I.: Helyünk és sorsunk a Duna-medencében. Budapest 1996

RomsiCs I. (Hrsg.): Trianon és a magyar politikai gondolkodás 1920-1953. Budapest 1998

ROMSICS I.: Nagyhatalmi politika és Magyarország a II. világháború alatt és után. In: FISCHER F. - MAJOROS J. VONYÓ J. (Hrsg.): Magyarország a /nagy/hatalmak erőterében. Tanulmányok Ormos Mária 70. születésnapjára. Pécs 2000, 521-533.

RomsICS I.: A trianoni békeszerződés. Budapest 2001

Romsics I.: The Paris Peace Treaty of 1947. Hungarian Studies in English 1, 2003, 57-64.

Romsics I.: Der Friedensvertrag von Trianon. Herne 2004

RÓNAI A.: Új felvidéki határunk. Földrajzi Közlemények 67. 6. 1939, 190-200.

RÓNAI A.: Térképezett történelem. Budapest 1993

Rosental, S.: La révision du Traité de Trianon, est-elle possible? Paris 1934

RudinszKY, J.: La révision du Traité de Trianon: l’article 19 du Pacte de la Société des nations. Paris 1933

SALKOV, A. P.: SSSR i natsionalno-territorialnoje pereustroistvo v Jugo-Vostotsnoj Jevrope (1938-1941).

Otjetsestvennaja istorija 3/2005, 71-83.

SALLAI G.: Az első bécsi döntés diplomáciai és politikai előtörténete. Századok 134/2000, 597-631.

SALLAI G.: Az első bécsi döntés. Budapest 2002

SAVADJIAN, L.: The Campaign against the Treaty of Trianon. Revue des Balkans. Paris 1929

SCELLE, G: Le litige roumano-hongrois devant le Conseil de la Société des nations. Genève 1927

SCHLAG, G.: Die Kämpfe um das Burgenland. Wien 1970

SCHMIDT, P.: Hitler tolmácsa voltam. Budapest 1971

SCHMID, K.: Die Slowakische Republik 1939-1945. Eine staats- und völkerrechtliche Betrachtung. I-II. Bde. Berlin 1982

SCRIMALI, A.: La revisione del Trattato del Trianon. Palermo 1934

Seton-Watson, R. W.: The New Slovakia. Prague 1924

Shvoy Kálmán titkos naplója és emlékiratai, 1919-1945. Budapest 1983 
SIDOR, K.: Slovenská politika na pôde pražského snemu. I. Bratislava 1943

SiNGER, B.: Peace Treaty with Hungary. Chicago 1920

Sipos P.: Imrédy Béla és a Magyar Megújulás Pártja. Budapest 1970

SIPOS P.: Az Imrédy kormány válsága és bukása. Történelmi Szemle 9/1966, 42-84.

SiPOS P. (Hrsg.): Keitel vezértábornagy visszaemlékezései. Budapest 1997

SiPOS P.: Imrédy Béla. Politikai életrajz. Budapest 2001

Soós K.: Burgenland az európai politikában, 1918-1921. Budapest 1971

STEIER L:: A tót kérdés. Liptószentmiklós 1942

SWOK, R.: Interprétations de la politique étrangère de Hitler. Une analyse de l'historiographie. Paris 1987

SZABÓ H.: A visszacsatolt Csallóköz politikai és közigazgatási beilleszkedése 1938-1941. Fórum

Társadalomtudományi Szemle 2/2002, 35-58.

SZANA, A.: Die Geschichte der Slowakei. Bratislava 1930

SZARKA L.: Magyarország és a magyar kisebbségek ügye a párizsi béketárgyalásokon: határkijelölés, népszavazás, kisebbségvédelem. In: BÁRDI N. - FEDINEC Cs. - SZARKA L. (Hrsg.): Kisebbségi magyar közösségek a 20. században. Budapest 2008

SZEGEDY-MASZÁK A.: Az ember ősszel visszanéz...Egy volt magyar diplomata emlékirataiból. I-II. k. Budapest 1996

TArdieu, A: La Paix. Paris 1921

TeleK J.: Peace by Negotiation: Did the Paris Peace Conferences and Peace Treaties Help Maintain Peace after the Two World Wars? The Example and Fate of Hungary. Hungarian Historical Studies. Toronto 1989

TeleK J.: Trianon and Canada: The Treaty of Trianon and Reaction to It in Canada Seventy Years Ago Revisited. Hungarian Historical Studies. Toronto 1991

Tihany, L. C.: The Baranya Dispute, 1918-1921: Diplomacy in the Vortex of Ideologies. New York 1978

Tilkovszky L.: Revízió és nemzetiségpolitika Magyarországon. 1938-1941. Budapest 1967

TilkovsZKY L.: Teleki Pál. Legenda és valóság. Budapest 1969

TilkovszKy, L.: Teufelskreis. Die Minderheitenfrage in den deutsch-ungarischen Beziehungen. Budapest 1989

Tisseyre, Ch.: Une erreur diplomatique: la Hongrie mutilée. Paris 1922

TÖnSmeYer, T.: Das Dritte Reich und die Slowakei 1939-1945. Politischer Alltag zwischen Kooperation und Eigensinn. Paderborn 2003

Trianon and East Central Europe: Antecedents and Repercussions. New York 1995

ÚJPÉTERY E.: Végállomás Lisszabon. Hét év a magyar királyi külügy szolgálatában. Budapest 1987

UlLEIN-REVICZKY, A.: La nature juridique des clauses territoriales du Traité de Trianon. Paris 1929

UlLEIN-REVICZKY A.: Német háború - orosz béke. Budapest 1993

VARGa Zs.: La tragédie d'un pays millénaire. Paris 1932

VARGa Zs.: La valeur morale du Traité de Trianon et la violation de ses termes. Paris 1932

VARGA J.: Bűnös nemzet, vagy kényszerû csatlós? 1. k. Budapest 1991

VARSIK, B.: Die slovakisch-magyarische ethnische Grenze in den ketzten zwei Jahrhunderten. Bratislava - Pressburg 1940

VÁVRA - EIBEL: Viedenská arbitraz - dosledok Mníchova. Bratislava 1963

VIEST, R.: Predohra k viedenskému diktátu. Nové časy. Nov. 1, London 1942

VIETOR, M.: Dejiny okupácie juzneho Slovenska 1938-1945. Bratislava 1968

VNUK, F.: Slovenská otázka na západe 1939-1940. Cleveland 1974

WeINBeRG, G. L.: The Foreign Policy of Hitler's Germany. Starting World War II, 1937-1939. Chicago 1980

ZEIDLER M.: A magyar revíziós gondolat. Budapest 2001

ZEIDLER M.: A magyar irredenta kultusz a két világháború között. Budapest 2002

ZELLNER, J. M.: Eigenständigkeit Ungarns oder Satellit des Dritten Reiches? Zum deutsch-ungarischen Verhältnis 1939-1944. Ungarn-Jahrbuch 29/2008, 201-257.

ZEMAN, Z. - KLÍMEK, A.: The Life of Edvard Beneš 1884-1948: Czechoslovakia in Peace and War. Oxford 1997

ZSELICZKY B.: Kárpátalja a cseh és szovjet politika érdekterében. 1920-1945. Budapest 1998

ZsigA T.: Az első király-puccs és Vas megye (1921). Vasi Szemle 2/1979 269-286.

ZsIGA T.: Horthy ellen, a királyért. Budapest 1989 